\title{
Remote sensing and in situ mineralogic survey of the Chilean salars: An analog to Mars evaporate deposits?
}

Flahaut J. ${ }^{1,2^{*}}$, Martinot M. ${ }^{1,2}$, J.L. Bishop ${ }^{3}$, G.R. Davies ${ }^{1}$, N.J. Potts ${ }^{1,4}$

1- Faculty of Earth and Life Sciences, Vrije University Amsterdam, The Netherlands

2- Univ Lyon, Université Lyon 1, ENS-Lyon, CNRS, UMR 5276 LGL-TPE, F-69622, Villeurbanne, France

3- Carl Sagan Center, The SETI Institute, Mountain View, CA 94043, USA

4- School of GeoSciences, University of Edinburgh, King's Buildings, Edinburgh, EH9 3FE, UK

*Corresponding author: Dr Jessica Flahaut, Laboratoire de Géologie de Lyon: Terre, Planètes, Environnement, Université Lyon 1, 2, rue Raphaël Dubois, 69622 Villeurbanne cedex, France. Email : jessica.flahaut@ens-lyon.org

\section{Keywords}

Atacama, Mars, Chile, analog, spectroscopy, XRD, sulfates, chlorides, salts

\section{Abstract}

The identification and characterization of hydrated minerals within ancient aqueous environments on Mars are high priorities for determining the past habitability of the planet. Few studies, however, have focused on characterizing the entire mineral assemblage, even though it could aide our understanding of past environments. In this study we use both spaceborne and field (VNIR spectroscopy) analyses to study the mineralogy of various salt flats (salars) of the northern region of Chile as an analog for Martian evaporites. These data are then compared to laboratory based Raman 
and XRD analyses for a complete overview on mineral assemblages. Central (core) and marginal zones within the salars are easily distinguished on the Landsat 8 band color composites. These areas host different mineral assemblages that often result in different landscapes. The lower elevation Salar de Atacama, located in the Andean pre-depression, is characterized by a unique thick halite crust at its center, whereas various assemblages of calcium sulfates (gypsum, bassanite, anhydrite) and sodium sulfates (mirabilite, thenardite, blodite, glauberite), borates (ulexite, pinnoite), $\mathrm{Al} / \mathrm{Fe}-$ clays and carbonates (calcite, aragonite) were found at its margin. Sulfates form the main crust of the Andean salars to the east, although various compositions are observed. These compositions appear controlled by the type of feeder brine $\left(\mathrm{Ca}, \mathrm{SO}_{4}\right.$ or mixed), a result of the local geology among other factors. Sulfate crusts were found to be generally thin $(<5 \mathrm{~cm})$ with a sharp transition to the underlying clay, silt, or sand-rich alluvial deposits. Coupled with morphologic analyses, VNIR spectroscopy provides a powerful tool to distinguish different salt crusts. XRD analysis allowed us to quantify the mineral assemblages and assess the limitations of VNIR techniques in the presence of hydrated sulfates, which tend to mask the signatures of other minerals such as clays, chlorides, and carbonates. We found that the Atacama's unique arid and volcanic environment, coupled with the transition recorded in some of the salars has a strong Mars analog potential. Characterizing the outcrop mineralogy at a variety of environments from alkaline, lake waters to more acidic salar brines may help in constraining geochemical environments on Mars.

\section{Introduction}

Remote sensing and in situ data from past and current Mars orbiter and lander missions have provided extensive evidence for the presence of water-lain sedimentary rocks on Mars (Carr and Head, 2010, and references therein). Infrared technology has been utilized to detect hydrated minerals, including phyllosilicates, carbonates, sulfates, and chlorides in specific areas of the Martian surface (Poulet et al., 2005; Gendrin et al., 2005; Osterloo et al., 2008, Murchie et al., 2009; Ehlmann et al., 2008, 2011; Carter et al., 2010, 2013). These minerals are generally found in Noachian $(\sim 4.1-\sim 3.7$ Gy) and Hesperian-aged ( 3.7- 3.0 Gy) terrains, although younger, more localized outcrops have also been detected (e.g., Murchie et al., 2009, Carter et al., 2013). Coupled 
with morphological evidence for ancient lakes and valleys (e.g., Fassett and Head, 2008; Hynek et al., 2010), this key observation has led to the hypothesis that Mars likely underwent major climate change, and could have experienced warmer, wetter, and more habitable conditions in its past $(<3.7$ Gy) (Bibring et al., 2006). The nature and timing of this potential, planetary-scale, climate change is a major outstanding question in current Mars studies. In an attempt to better interpret the exact environmental conditions for the formation of hydrated minerals on the Martian surface, terrestrial analogs were examined.

The region of northern Chile/Central Andes (including the Atacama desert) is characterized by a succession of north-south trending mountain ranges and closed basins. The central parts of the basins are infilled by evaporate deposits or occupied by saline lagoons, collectively referred to as salars. Receiving only a few millimeters of rain per year, and being spread along a volcanic ridge, this region appears similar to some Martian paleo-environments (Ericksen, 1983; Stoertz and Ericksen, 1974). Martian sulfate and chloride-rich deposits may have formed through similar processes to those that formed the salars salts and appear to share common features and mineralogy (e.g., Sutter et al., 2007). Future Mars research should benefit from a detailed terrestrial analog survey that permits a full understanding of the geological context, mineralogical assemblages, and the geochemical and environmental processes responsible for the formation of evaporate deposits in enclosed settings, under arid conditions.

To that end, we performed an in-depth combined remote sensing and in situ analytical study of five salars located within the Antofagasta region of Northern Chile. Our site selection includes the largest salar, the Salar de Atacama, formed at intermediate elevations $(2500 \mathrm{~m})$ under dry and hot conditions, and located on sedimentary basement, as well as various salars located at higher elevations (> $4000 \mathrm{~m}$ ) within the slightly wetter Andean volcanic highlands. We report the mineralogy and morphological characteristics of each salar as observed from space and in the field and discuss the mineral zonation and intra-salar variations as a function of environmental parameters (source type, temperature, elevation, evaporation rate etc.). The ultimate objective of this study is to correlate the remote and field observations made in the salars and interpret their variations in term of 
the overall geochemical and sedimentary environment. By comparing features and assemblages with observations made on Mars we aim to be able to place constraints on past Martian environments and their habitability potential.

\section{Regional context}

The subduction of the Nazca Plate below the South American Plate resulted in the formation of north-south trending compressional features, including the Andean orogenic belt. The high topography of the Andes has a major impact on the climate of South America, referred to as the rainshadow effect. Whereas lands to the north are wet and warm, lands on the western side of the Andes barrier (including the Atacama desert) are extremely hot and dry. This effect is enhanced by the action of the upwelling, northwest-flowing, cold Pacific Humboldt current that inhibits the moisture capacity of onshore winds and prevents precipitations (e.g., Houston and Hartley, 2003; Armijo et al., 2015). The Atacama Basin is estimated to have a mean annual precipitation below $50 \mathrm{~mm}$ and an average temperature of about $11^{\circ} \mathrm{C}$ (Stoertz and Ericksen, 1974). It is one of the oldest deserts on Earth and has experienced extremely arid conditions for at least 15 My (Houston and Hartley, 2003). The presence of water in the Atacama desert and surrounding regions is rare, only occuring as nearsurface groundwater or occasional transient rivers draining from the Andes (Houston, 2006). The semi-arid high Andean reliefs contain > 100 basins with interior drainage; most contain saltencrusted playas referred to as salars. The Atacama desert is defined as the plateau of northern Chile located between the Andes and the Pacific coast. Hills and valleys in the Atacama desert are covered with extensive saline crusts of diverse types (Stoertz and Ericksen, 1974). Because it is the driest non-polar desert on Earth, the Atacama desert has been used as an analog for martian and lunar environments over the past two decades (e.g., Wettergreen et al., 1999; Navarro-Gonzales et al, 2003; Piatek et al., 2007; Wynne et al., 2008).

The present study area is located in the Antofagasta region of Chile, north of the Atacama region, south and east of the San Pedro de Atacama village, between -23 and $-24^{\circ}$ latitude, and -68.8 and $67.3^{\circ}$ longitude (Figure 1). This area of northern Chile is underlain by marine Cretaceous rocks, as well as rhyolitic to basaltic rocks in the Andean highlands (Stoertz and Ericksen, 1974). The main 
morpho-structural units in this region of Chile, are, from west to east: (1) the Coast Range, (2) the Central Depression or Central Valley, (3) the Precordillera (also referred to as the Domeyko Range), (4) the pre-Andean Depression, (5) the Western Cordillera, (6) the Altiplano, and (7) the Eastern Cordillera (Risacher et al., 2003, figure 1). Most of the major reliefs formed as a result of the late Tertiary to Holocene faulting, accompanied by the uplift of Cordillera Domeyko Range. Our study area includes portions of the pre-Andean Depression (Atacama basin) and of the Andean highlands (also called the Western Cordillera) and encompasses the main salar, the Salar de Atacama, as well as several high elevation, smaller scale salars (including the Salar de Quisquiro, Laguna Tuyajto, Salar de Laco, Salar de Aguas Calientes 3), (Figure 1). The study area is predominantly underlain by Tertiary and Quaternary rhyolotic and dacitic ignimbrite sheets and covered by numerous andesitic stratovolcanoes, reaching up to $6500 \mathrm{~m}$ in elevation. Native sulfur deposits are found throughout the area and were mined at the Cerro Toco (white arrow on figure 2a). The Atacama basin is filled with Tertiary to Quaternary (or Cenozoic) alluvium and lacustrine sediments (Stoertz and Ericksen, 1974, Risacher et al., 2003) and represents the largest structural basin in the area. The basin is fringed to the west by the Cordillera de la Sal, a former evaporate body that was faulted and folded as a result of compression during the Cenozoic (Dingman, 1962, 1967), and that includes the famous Lunar Valley and Death Valley sites.

Our study area differs from previous Mars analogs studies that focused on the Central Depression, between the Coast Range and the Domyeko Range, near the ghost town of Yungay (e.g., NavarroGonzales et al, 2003; McKay et al., 2003, Sutter et al., 2007, Piatek et al.,2007; Figure 1). The Central Valley, which is comprised of a thick fill of Tertiary to Holocene detrital and lacustrine sediments, was not considered in the present study as multiple authors (Eriksen, 1981, Berger and Cooke, 1998; Rech et al., 2003, Bao et al., 2004, Michalski et al., 2004) have pointed out the possible influence of an oceanic source on the formation of local evaporate deposits; this is not thought to be applicable to martian environments. 


\section{Method}

\subsection{GIS setting}

Available remote sensing datasets and maps were gathered into a geographic information system (GIS) that enables management of the data and also supports simultaneous visualization and analyses of various data of diverse types. Field data were collected on a tablet using the GIS pro application (Garafa) and later integrated into our GIS.

Remote sensing data from imaging satellites were used to map and characterize the Atacama salars from space. ArcGIS (ESRI) world imagery maps (including 15 meters/pixel TerraColor imagery at small and mid-scales, and DigitalGlobe 1 meter/pixel imagery at large scale) and data (boundaries, places) were used as a background (more information is available at http://www.arcgis.com/home/item.html?id=10df2279f9684e4a9f6a7f08febac2a9; Source: Esri, DigitalGlobe, GeoEye, Earthstar Geographics, CNES/Airbus DS, USDA, USGS, AEX, Getmapping, Aerogrid, IGN, IGP, swisstopo, HERE, DeLorme, MapmyIndia, @OpenStreetMap contributors, and the GIS user community). Landsat imagery has previously been demonstrated to be efficient at mapping salar zonation (e.g., Chapman et al., 1989) and was, therefore, used to survey the terrain diversity from space and select representative field sites. The recent Landsat 8 reflectance data provide full coverage of the area at multiple wavelengths (Figure 1). The Landsat 8 satellite is equipped with two push broom sensors, the Operational Land Imager (OLI), that covers nine VNIR channels at 15-30 m spatial resolution, and the Thermal Infrared Sensor (TIRS), whose two thermal bands enable thermal wavelength atmospheric correction at a resolution of $100 \mathrm{~m}$ (Irons et al., 2012). Orthorectified and terrain corrected Level 1T OLI imagery was obtained from the USGS EarthExplorer (http://earthexplorer.usgs.gov/). VNIR bands 1 to 7 were converted to surface reflectance using the USGS L8SR on demand tool, that produces provisional Landsat 8 Surface Reflectance (SR) product (USGS, 2015).

\subsection{Field sampling and field VNIR spectroscopy}

Field sites were first selected based on their spectral diversity as suggested by Landsat imagery, then refined based on their accessibility, in terms of available roads or tracks, protected natural areas, and 
potential landmines. A total of $\sim 50$ sites in 5 different salars were visited during a field campaign that was carried out in February-March 2015 with the local support of ESO/APEX (Table 1). Several E-W and N-S transects were undertaken in the main salar, the Salar de Atacama (mixed brines), which lies at relatively low elevation $(2500 \mathrm{~m})$ on a sedimentary basement (Figure 1). In addition, four salars were visited at higher elevations $(>4000 \mathrm{~m})$ in the Andean highlands: the Salar de Quisquiro (Ca-brines), the Laguna Tuyajto ( $\mathrm{SO}_{4}$-brines), the Salar de Laco ( $\mathrm{SO}_{4}$-brines), and the Salar de Aguas Calientes 3 (mixed brines) (Figure 1d). For each salar, we performed (where possible) transects out from the center towards margins to collect spectroscopy measurements and samples. The location and morphology of the outcrops was documented with the GIS pro application including field pictures, while the in situ mineralogy was derived from VNIR reflectance spectra measured with an Analytical Spectral Devices (ASDinc) field spectrometer. The ASDinc Fieldspec 4 Hi-Res instrument collects visible and near-infrared (VNIR) spectra in the $350-2500 \mathrm{~nm}$ spectral domain with three detectors (VNIR: 300-1000, SWIR-1: 1000-1800, SWIR-2: 1800-2500 nm) and has a spectral resolution of $3 \mathrm{~nm}$ in the $350-1000 \mathrm{~nm}$ range, and $8 \mathrm{~nm}$ in the $1000-2500 \mathrm{~nm}$ range. All spectra were acquired in the field at a distance of $\sim 10 \mathrm{~cm}$ from the outcrops, using the bare fiber inserted directly in the pistol grip, which produces a 25 degree field of view (FOV). As the atmospheric water vapor content is very low $(<$ a few \%) in the Atacama there was no need for a contact probe. A $100 \%$ white panel was used for calibration prior to every set of measurements. From each outcrop a set of 5 to 10 spectra were acquired from different locations to assess the outcrop homogeneity. Spectra were converted from radiance to reflectance using the ASDinc software and compared with the VNIR spectra of reference minerals from the USGS and CRISM spectral libraries (Clark et al., 2007; Murchie et al., 2007). All field VNIR spectra correspond to single measurements and are presented unsmoothed, in units of absolute reflectance, and uncorrected for atmospheric gases, as their effect is only minor.

Samples were collected in sealed tubes and bags at each site to be further characterized by Raman spectroscopy and X-Ray diffraction in the laboratory. Additional samples were collected and preserved in sterile conditions for a complementary astrobiologic investigation performed jointly 
with Leiden University and the European Space Agency (Martini et al., 2016, Monaghan et al., in prep.). For this purpose eight samples were also collected at a $20 \mathrm{~cm}$ depth below salar crusts at 7 different sites.

\subsection{Raman spectroscopy}

Selected samples, collected from the field, were taken from sealed containers under a nitrogen atmosphere (to avoid atmospheric water contamination) and measured with a Renishaw InVia Reflex confocal Raman microscope (Wotton-under-Edge, United Kingdom) at the Vrije University Amsterdam, the Netherlands. Spectra were recorded using a $80 \mathrm{~mW}$, 532-nm frequency doubled Nd:YAG excitation source in combination with a $1800-1 / \mathrm{mm}$ grating and a Peltier cooled CCD detector $(203 \mathrm{~K})$. The $521 \mathrm{~cm}^{-1}$ Raman shift of an internal silicon standard was used to verify the spectral calibration of the system. Spectra were compared with the Raman spectra of reference minerals present in the RUFF libraries and in the WURM database (Downs and Hall-Wallace, 2003; Caracas et al., 2011).

\subsection{X-ray diffraction}

Semi-Quantitative X-ray diffraction (XRD) analyses were conducted to determine the composition and relative abundance of the various salts. Selected samples were dried at $70^{\circ} \mathrm{C}$ for 48 hours, ground in an agate mortar, dry sieved to $<100$ microns and measured using a Bruker D8 Advance diffractometer equipped with an X-ray $\mathrm{Cu}$ source at the Centre de Diffractométrie of the University Lyon 1, France. Disoriented measurements were made over a 2 Theta range of $3^{\circ}$ to $70^{\circ}$. XRD patterns were analyzed using the Bruker DIFFRAC.SUITE EVA software. Mineralogical fits were performed by comparing d-spacing values to those of minerals listed in the International Center for Diffraction Data database and the Crystallography Open Database (Kabekkodu et al., 2002; Grazulis et al., 2009). Basic mineralogy and crystallinity were derived from the analyses, with the exception of clay mineralogy, which would require a different technique of XRD analysis. Mineral abundance was determined as weight percent (wt. \%) using the Rietveld method, with a 10 to $20 \%$ accuracy. 


\section{Results}

\subsection{Remote sensing observations}

Salars in the study area are easily mapped from space due to their high albedo and being confined within topographic lows. In Landsat imagery, salars are also easily distinguished from their surroundings, which are mostly volcanic in nature. Previous studies have demonstrated the potential of Landsat Thematic Mapper data to map compositional zoning within the Salar de Llullia-Ilaco (Chapman et al., 1989) and the Salar de Atacama (Houston, 2006). Bands 4, 5 , and 7 (at $0.772-$ $0.898,1.547-1.749$ and $2.064-2.345 \mu \mathrm{m}$ respectively) were found to be efficient at capturing the majority of the mineralogical information and were used as color composites to map the different evaporate mineral zones within the salars. In this study, we make use of the equivalent bands on the Landsat 8 instrument by performing a 5,6,7 band color composite (Figure 2) (bands are at 0.851$0.879,1.566-1.651,2.107-2.294 \mu \mathrm{m}$ respectively). Landsat 8 image LC82330762014345 covers the Salar de Atacama to the east as well as most of the Andean salars, including the four in our study. Core and marginal zones within the salars are easily distinguished on the RGB color composite, and mapped as different colors (Figure 2a). Previous field investigations (e.g., Houston, 2006) and present investigations confirm that distinct mineral assemblages are observed within specific zones of an individual salar, with the exception of the red zones that correspond to wet soils. Distinct mineral assemblages are also observed between the various salars. Surrounding volcanic terrains appear in various tones of black, gray, green, and blue (Figure 2a).

The lower elevation Salar de Atacama, located in the Andean pre-depression, is characterized by a unique, thick halite crust at its center (gray color on the Landsat 5,6,7 RGB, Figure 2a), whereas various assemblages of sulfates or mixed sulfates and chlorides (white tones) and clays/carbonates (yellow tones) were found at its margin. Most of the Andean salars are mapped in tones of white, orange and red on this color composite, suggesting wet soils and a composition possibly closer to the margins of the Salar de Atacama (Figure 2a). Houston (2006), however, suggested that the lower albedo of the Salar de Atacama core (gray on Figure 2a) could be a result of dust covering on the old 
halite crust, and that a halite crust that was frequently inundated and re-crystallized should have a higher albedo and appear in tones of white, like some of the salts at the margins.

Consequently, parameters were developed to highlight the possible differences between the Andean salars and the Salar de Atacama margins on the Landsat 8 data (Figure 2c,d). Band ratios 4/7 and 5/7, which are adapted from previous Landsat sulfate parameters (Amos and Greenbaum 1987, Mougenot et al. 1990, Mougenot, 1993) show high values in the some of the Andean salars (Laco, Tuyajto, Aguas Calientes 3) and on the eastern margin of the Salar de Atacama and other salars (e.g., Quisquiro, Aguas Calientes 2) (Figure 2c). The Salar de Quisquiro and Salar de Aguas Calientes 2 have low values in their central parts, that correlate with lower albedo material on the visible optical imagery. Based on previous work (Epema, 1986, 1990; Mougenot et al., 1990), band ratios 5/2 and $4 / 2$ should also help track the effect of salt dilution on soils. These ratios have higher values in the Andean highlands, likely highlighting the difference in bedrock composition with the eastern Atacama basin, which is underlain by sediments (Figure 2d).

\subsection{Field observations}

A variety of salt crusts have been observed and previously reported in the northern Chilean salars (e.g., Stoertz and Ericksen, 1974). Soils in the Atacama desert are either covered by salt-rich fines or cemented by a hard saline crust. In the present study area, salt crusts were found to be generally thin $(<5 \mathrm{~cm})$ with a sharp transition to underlying clay, silt or sand-rich alluvial deposits. The only exception lies within the Salar de Atacama, where the lower limit of the hard (halite) crust could not be observed, but is estimated to be at least a few meters deep (Stoertz and Ericksen, 1974).

Salt crusts were classified in the field into multiple types based on their morphology (Figure 3,4). The main categories include (1) thick, sharp, blocky, hard crust (red squares in Figure 3), (2) thick, smooth, hard crust (magenta square in Figure 3), (3) thin, dry and friable soft crust (dark blue squares in Figure 3), (4) smooth, moist soft crust (green squares in Figure 3). Other common terrain types include (5) muddy surfaces with polygonal cracks, sometimes covered with thin salt deposits accumulated in topographic lows (light blue squares in Figure 3), and (6) $\mathrm{cm}$-scale rock pebbles 
forming a beach near the water (purple square in Figure 3). To the first order these morphologies correlate to mineralogy based on field spectra (cf. next section).

Type 1 is a hard saline crust, which was mostly observed in the field within the core section of the Salar de Atacama (Figure 4 a-d). This crust is massive, $>10$ 's of centimeters to meters thick, and made of sharp, irregular blocks with clinkerlike texture, forming a rugged, hummocky surface (Figure 4a, b). Stoertz and Ericksen (1974) noticed that this crust is usually associated with the zone of chlorides, in permanently (or nearly) dry areas. Type 1 crusts appear in dark tones on the aerial and spaceborne images as they are older and generally covered by a thin layer of dust or sand from the underlying sediments, which are trapped in pits (Figure 3a, h). At the hand specimen scale, outcrops are characterized by colorless crystals, consistent with halite, sometimes covered or containing brown sediments. On the eastern part of the Salar de Atacama, this crust transitions to a Type 3 crust in an area where the crust appears less rugged, and is characterized by half a meter scale polygons with upturned edges and layering of the massive rock salt in the upper $5 \mathrm{~cm}$ (Figure $4 c, d)$. White, high purity rock salt can be seen in the central, flat part of the polygon, suggesting recent salt precipitation. Spaceborne images suggest Type 1 crust could also be present in the Salar de Aguas Calientes 1 and 2, Salar de Capur and in parts of the Salar de Quisquiro that were not accessible in the field but appear dark-toned on visible space imagery (Figure 3a, b, c, d, e, h).

Type 2 is a thick but smooth, flat hard crust, and was observed in the core area of the Laguna Tuyajto (Figure 4e, f). This type of crust was wet, suggesting that pure salt are nearly continuously renewed at the surface. This crust appears white on visible images (Figure 3a, f). This crust is a few centimeters thick, and fractured by meter-scale polygons. Fractures between the polygons appear randomly oriented and infilled with salts. Based on spaceborne visible and Landsat imagery, this very white, wet crust could also be present in the inaccessible Salar de Capur (Figure 3e).

Type 3 is a soft, dry friable crust, that was observed at the margins of the Salar de Atacama, Salar de Quisquiro, Salar de Laco and Salar de Aguas Calientes 3 (Figure 3, 4g-i). The surface in these areas appears undulated at a scale of about $20 \mathrm{~cm}$ and rigid. This crust is, however, easily crumbled with fingers into a loose dry powder. In contrast to Types 1 and 2, Type 3 crusts are not made up of 
nearly pure salt, but rather consist of the underlying sands or silts cemented together in the upper centimeter. Less saline, moist material is found at depths of $20-30 \mathrm{~cm}$, suggesting that the surface is kept in a puffy condition by crystallization of salts in the capillary fringe of the water table (Stoertz and Ericksen, 1974). Previous authors (e.g., Goodall et al., 2000) have suggested that puffy and powdery textures (crust type 3) are consistent with salts formed by efflorescence; whereas crusts formed by precipitation more commonly show blocky or polygonal morphologies (crust type 1,2), consistently with our observations. A former, $1 \mathrm{~cm}$-thick carbonate-rich white crust was observed at $20 \mathrm{~cm}$ depth in the Salar de Laco, confirming the previous assumptions made on airborne images that this salar must have been occupied by a deeper lake in the past (Stoertz and Ericksen, 1974).

Type 4 is a smooth, moist crust and is observed in marginal zones, close to water ponds and lagoons, in the Salar de Atacama (near Laguna Cejar and Laguna Piedra), Laguna Tuyajto and the Salar de Quisquiro (Figure 4j-1). These areas are characterized by a shallow fluctuating groundwater table that keeps the surface moist (Stoertz and Ericksen, 1974). Type 4 crusts are extremely thin and show various color shades in the field (from white to dark gray) and on spaceborne images, suggesting variable saline contents or types, or suggesting the substrate is showing through (Figure $3,4 \mathrm{j}-1)$. Gypsum-rich ramparts sometimes terminate this crust at the edge of the saline ponds.

Type 5 terrains consist of clastic sediments, ranging from clay, silt and fine sand (clay playa) to coarser sands and gravels (lake sediments) (Figure 4m-o). Clay playas are often marked by mudcracked polygons (10's of $\mathrm{cm}$ scale, smaller than the polygons seen in halite-rich terrains of crust type 1 and 2) and are observed in the marginal areas of the Salar de Atacama, salar de Laco and Laguna Tuyajto (Figure 3a, f, g, h). Clay playa result from the infrequent flooding of marginal areas, creating extensive ephemeral lakes, that can dry up in a few days to weeks (Stoertz and Ericksen, 1974). Coarser clastic sediments are observed in the most distal part of Laguna Tuyajto and beneath the salt crust of most salars. Erosion of the surrounding high volcanoes during storms that trigger mudflows is likely the source of these lake sediments. A thin, patchy, white saline material is sometimes accumulated in topographic lows suggesting temporary rises of the groundwater table in these marginal areas (Figure 4o). 
Type 6 terrain is made of cm-scale angular pebbles, and was observed next to the water pond in the Salar de Aguas Calientes 3. It is interpreted as a local, beach facies (Figure $3 \mathrm{e}, 4 \mathrm{p}, \mathrm{q}$ ).

Our observations, derived from field observations at five salars and spaceborne imagery, are consistent with the many observations made by Stoertz and Ericksen (1974, their figure 11) based on aerial imagery and field observations at the Salar de Atacama. A few differences on the distribution of hard and soft crusts are observed and can be attributed to changes over time, given that at the time of their research there was no water body (and a hard crust) in the Laco and Tuyajto locations, but there was an ephemeral lake in the south-east part of the Salar de Atacama, that we did not observe (mapped as a clay playa, figure $3 \mathrm{~h}$ ).

\subsection{VNIR spectroscopy}

Over a hundred VNIR spectra were acquired in the field; a representative set is presented in Figure 5, along with a comparison to reference spectra from the USGS spectral library (Clark et al., 2007). Most of the samples show absorption features around 1.4 and $1.9 \mu \mathrm{m}$, and eventual overtones around 0.97 and $1.2 \mu \mathrm{m}$, that are attributed to adsorbed water and hydrated minerals in general (e.g., Hunt and Salisbury, 1970; Figure 5b). The relative strength of these two absorptions, the symmetry of the bands and the positions of the absorptions centers vary with the mineral structure and composition. In some samples (e.g., sample J2L2R3, J9L2R1, Figure 5b) the water saturation results in an additional features near $1.85 \mu \mathrm{m}$. Narrower absorptions in the $2.1-2.5 \mu \mathrm{m}$ domain are used to distinguish among the different types of $\mathrm{OH}$-bearing minerals.

Sulfates were identified thanks to a drop in reflectance at $2.4 \mu \mathrm{m}$ caused by vibrations of the $\mathrm{SO}_{4}$ group (e.g., Gendrin et al., 2005; Cloutis et al., 2006; Bishop et al., 2009). Although a similar feature can also be attributed to chloride salts or chlorine oxyanion salts (e.g., Lynch et al., 2015), additional absorptions allow for the identification of specific sulfate minerals. Ca-sulfates such as gypsum $\left(\mathrm{CaSO}_{4}, 2 \mathrm{H}_{2} \mathrm{O}\right)$ show a diagnostic triplet at 1.45, 1.49, and 1.54, single bands near 1.75 and 1.94 $\mu \mathrm{m}$, and a doublet at 2.22 and $2.27 \mu \mathrm{m}$ (Bishop et al., 2014a, Figure 5a). In bassanite $\left(\mathrm{CaSO}_{4}\right.$, $0.5 \mathrm{H}_{2} \mathrm{O}$ ), these bands are shifted towards shorter wavelengths and occur as a triplet at $1.44,1.47$ and $1.54 \mu \mathrm{m}$, single bands at 1.78 and 1.93, and a doublet at 2.16 and $2.26 \mu \mathrm{m}$ (Bishop et al., 2014a). 
Anhydrite $\left(\mathrm{CaSO}_{4}\right)$ often displays a band centered at $1.94 \mu \mathrm{m}$ due to adsorbed water. Additional absorptions also differ in Na-sulfates depending on their hydration state and additional cations that might be present. Thenardite $\left(\mathrm{NaSO}_{4}\right)$ in the USGS library shows diagnostic absorptions at 1.42 , 1.94 and $2.11 \mu \mathrm{m}$ indicating it is partially hydrated, whereas mirabillite $\left(\mathrm{NaSO}_{4}, 10 \mathrm{H}_{2} \mathrm{O}\right)$ shows diagnostic absorptions at 1.46, 1.77, 1.96 and $\sim 2.2 \mu \mathrm{m}$ (Figure 5e). Reference libraries are incomplete for mixed sulfates but bloedite $\left(\mathrm{Na}_{2} \mathrm{Mg}\left(\mathrm{SO}_{4}\right)_{2}, 4 \mathrm{H}_{2} \mathrm{O}\right)$ is present in the USGS spectral library and shows absorptions at 1.47, 1.7 (broad), 1.96, 2.09, and $2.44 \mu \mathrm{m}$ (Figure 5b, Clark et al., 1990, 2007; Cloutis et al., 2006). Anhydrous chlorides and perchlorates (e.g., $\mathrm{NaCl}, \mathrm{MgCl}_{2}, \mathrm{NaClO}_{4}$ ) show little to no features in the VNIR domain except for adsorbed water features (Drake, 1995, Bishop et al., 2014c, Figure 5b,c). Na-, Ca-, Fe- and Mg- bearing chloride hydrates share some spectral absorptions with sulfates near 1.19, 1.45, 1.96 and $2.42 \mu \mathrm{m}$ (Hanley et al., 2014, 2015; Bishop et al., 2014b).

Borates have also been previously reported in the Chilean salars. Na-borate spectra exhibit overtones/combinations of the $\mathrm{B}-\mathrm{O}$ vibrations in the $1.55,1.75,2.15$, and $2.25 \mu \mathrm{m}$ regions (Cloutis et al., 2016). Ulexite $\left(\mathrm{NaCaB}_{5} \mathrm{O}_{6}(\mathrm{OH})_{6}, 5 \mathrm{H}_{2} \mathrm{O}\right)$ and pinnoite $\left(\mathrm{MgB}_{2} \mathrm{O}_{4}, 3 \mathrm{H}_{2} \mathrm{O}\right)$ spectra are characterized by a strong decrease in reflectance from 0.5 to $2.5 \mu \mathrm{m}$ and absorption features at $1.43-1.46$ (doublet), 1.96, 2.13-2.18 (doublet), $2.25 \mu \mathrm{m}$ for ulexite, 1.44, 151-1.55 (doublet), 1.64, 1.98, 2.13 2.22 (doublet) for pinnoite (Crowley, 1990; Clark et al., 2007; Figure 5d).

Carbonates and clays can be identified by their metal-OH absorptions in the 2.1-2.5 $\mu \mathrm{m}$ domain. Smectite clays are commonly characterized by water absorptions centered at shorter wavelengths than sulfates $(1.40-1.41$ and $1.90-1.92 \mu \mathrm{m})$. In contrast to the Al-phyllosilicates that have a diagnostic Al-OH absorption band at 2.19-2.21 $\mu \mathrm{m}$, spectra of Fe- and Mg-rich phyllosilicates exhibit Fe-OH and $\mathrm{Mg}-\mathrm{OH}$ bands at longer wavelengths (e.g. Bishop et al., 2008, Figure 5e): 2.28$2.29 \mu \mathrm{m}$ for nontronite, $2.30-2.31 \mu \mathrm{m}$ for saponite, $2.31-2.33 \mu \mathrm{m}$ for serpentines, and 2.33-2.37 $\mu \mathrm{m}$ for chlorites. Carbonates are more easily identified by absorptions near 3.4-3.5 and 3.9-4.0 $\mu \mathrm{m}$, but can also be characterized by overtones near 2.30-2.33 and 2.50-2.53 $\mu \mathrm{m}$ (e.g., Gaffey, 1986, Ehlmann et al., 2008, 2009, Bishop et al., 2013; Figure 5f). 
All these minerals have been identified at diverse locations of the study areas. Broad absorptions at 1.43 and $1.93 \mu \mathrm{m}$ are observed in the spectra of the rocks collected in the Salar de Atacama (J1L1R1) and Salar de Quisquiro hard crusts (J11L1R4) and on the thin white salt deposits sometimes covering clay playas (e.g., J9L2R1). Those absorptions are characteristic of water, and given that all samples are morphologically consistent with halite, we interpreted those spectra as hydrated halite (Figure 5b). A few samples collected east of the Salar de Atacama (J7L10, J7L14) have absorptions centered at 1.46, 1.78, 1.98 and $2.24 \mu \mathrm{m}$ that are more consistent with $\mathrm{MgCl}_{2}$ (Figure 5c). Additional absorptions in many spectra are sometimes present near $2.2 \mu \mathrm{m}$ and could be attributed to a $\mathrm{Cl}-\mathrm{O}$ combination, an $\mathrm{Al}-\mathrm{OH}$ combination or an $\mathrm{Si}-\mathrm{OH}$ combination (Cloutis et al., 2006; Bishop et al., 2008). The location of the band center suggest the presence of clay impurities in many cases $(2.21 \mu \mathrm{m}$ absorption, J7L8, J2L2R4 on figure 5f). An additional band at $2.31 \mu \mathrm{m}$ in sample J1L1R2 (Figure 5f) is present and could be due to the presence of calcium carbonates or $\mathrm{Fe} / \mathrm{Mg}$-rich clays. Clays are detected in some of the clay-bearing playa thanks to their absorptions centered at 1.41, 1.91, $2.21 \mu \mathrm{m}(\mathrm{J} 7 \mathrm{~L} 4$, figure 5e), but most clay-bearing playas exhibit spectra with bands centered at longer wavelengths (e.g., bands at 1.42, 1.93 and $2.21 \mu \mathrm{m}$ in J8L1, Figure 5e), suggesting a mixture with additional material such as halite and sulfates. Gypsum is detected in the samples of all five salars in both dry and wet crusts (e.g., J5L1R4, J2L2R2, figure 5a), sometimes mixed with halite (e.g., J5L1R3, Figure 5a). The resulting spectra exhibit flat-bottomed absorption features at $1.94-1.98 \mu \mathrm{m}$ and a stronger 1.4 absorption feature relative to the $1.9 \mu \mathrm{m}$ feature. Absorptions at respectively $1.44,1.96,2.12-2.18 \mu \mathrm{m}$ and $1.44,1.74,1.94,2.12-2.22 \mu \mathrm{m}$ in some spectra of dry crust within the Salar de Atacama are best matched by the borates ulexite (J1L1R4, figure 5d) and pinnoite (J1L1R3, figure 5d).

Finally, a $0.68 \mu \mathrm{m}$ absorption is present in the spectra of two samples (J2L2R2 and J9L2R3, figure 5a) that were taken in wet areas, near water ponds located respectively at laguna Tuyajto and laguna Cejar. The samples contain green microbial mats visible with the naked eye; chlorophyl in those mats could be responsible for this sharp feature in the visible part of the spectra. 


\subsection{Raman spectroscopy}

Raman spectra are presented in Figure 6, along with a comparison to reference spectra from the American Mineralogist Crystal Structure Database available on RRUFF (Downs and Hall-Wallace, 2003). Since Raman spectra were acquired on raw rocks (unprepared samples), minerals were identified by their main peak, which is found around $970 \mathrm{~cm}^{-1}$ for borates, 990 for Na sulfates, 1008 for gypsum, 1015 for anhydrite, 1085 for calcite (Figure 6b). Distinguishing between different minerals within the same group is, however, challenging due to the precision of the instrument. Carotenoids were also detected in several samples of wet crusts thanks to a set of 3 peaks located around 1005, 1150 and $1510 \mathrm{~cm}^{-1}$ (e.g., Hooijschuur et al., 2015, Verkaaik et al., 2015).

\subsection{Quantitative analysis from XRD}

XRD analyses provide quantitative insights into the mineral assemblages within the crystalline phase of the samples. A list of key sample compositions is given in Table 2. With the exception of margins/clay-playa rocks and samples taken at depth, all samples have a crystallinity index $>90 \%$, indicating that they contain very little to no amorphous material. Gypsum and halite form the most abundant mineral phase for the majority of salar crusts, and are often coupled with calcium carbonates (calcite or aragonite). Additional carbonates such as natrite, natron and dolomite are detected in the samples of: the Salar de Aguas Calientes 3, Laguna de Cejar/ de la Piedra (Salar de Atacama), Laguna Chaxa (Salar de Atacama; Table 1), respectively. Detrital material (anorthite or albite, quartz) are present in most samples, with increasing proportions at the salar margins or at depth. Additional minor mineral phases include a range of $\mathrm{Ca}$ and $\mathrm{Na}$-sulfates such as bassanite (in the Salar de Atacama and Salar de Quisquiro), anhydrite (Salar de Atacama, Salar de Quisquiro, Salar de Aguas Calientes 3), alunite (lauguna Tuyajto), glauberite, hydroglauberite, bloedite, thenardite, mirabillite (Salar de Atacama), borates such as pinnoite, ulexite, nobleite (Salar de Atacama) and chlorides such as sylvite, hydrophilite (Salar de Atacama) (Table 2, Figure 7). 


\section{Discussion}

\subsection{Correlation between field (VNIR) and lab (Raman, XRD) analyses}

There is agreement with the mineralogy determined from Raman and VNIR analyses, with the exception of some carbonate-bearing samples that are difficult to characterize with VNIR compared to Raman analysis (e.g., sample J7L4; Table 3, figure 8). Raman data were a good indicator of the presence of anhydrous sulfates, such as anhydrite, which are difficult to identify solely by VNIR spectroscopy. Raman analyses were performed at a smaller scale (grain scale) than VNIR analyses, resulting in more heterogeneities in the analyses of a single sample. The measurements are, however, consistent with all of the minerals identified in the homogenized samples from the XRD analyses. Field observations were also a helpful complementary tool because some minerals such as halite displayed characteristic morphology that facilitate their identification.

For the Atacama salt crusts, VNIR and Raman spectroscopy were often redundant as most samples are well-crystallized. XRD analysis, however, provided significant additional information for these samples as 1) it allowed the detection of minerals that have featureless spectra in the VNIR domain such as halite, quartz, and anorthite, 2) it allowed the detection of all the most abundant mineral phases, 3) it allowed quantitative mineral abundance measurements. XRD analysis was also a powerful tool for distinguishing between different minerals within the same family (e.g., glauberite and hydroglauberite, thenardite and mirabillite). These minerals should have distinct VNIR properties, however, spectral libraries for sulfates are incomplete. Additionally, XRD analysis also distinguished between hydrated sulfates and hydrated $\mathrm{Cl}$ salts, which can have similar VNIR spectra, making detections sometimes problematic (e.g., Hanley et al., 2015; Lynch et al., 2015).

Laboratory XRD analysis also represents a powerful asset to estimate the benefits and limitations of VNIR spectroscopy; VNIR spectroscopy however represents an easy, rapid, passive and nondestructive tool during field surveys. Remote sensing VNIR spectroscopy is also commonly used in planetary sciences to survey the composition of surfaces (e.g., the OMEGA (Observatoire pour la Mineralogie, l'Eau, les Glaces et l'Activité), CRISM (Compact Reconnaissance Imaging Spectrometer for Mars) and M3 (Moon Mineralogy Mapper) instruments, see Bibring et al., 2004; 
Murchie et al., 2007; Pieters et al., 2009) and VNIR spectrometers, such as MicrOmega, MA-MISS (Mars Multispectral Imager for Subsurface Studies), ISEM (Infrared Spectrometer for ExoMars), LIS (Lunar Infrared Spectrometer) and SuperCam, are being developed for the next generation Mars and Moon landers and rovers (Pilorget and Bibring, 2013, De Angelis et al., 2014; Korablev et al., 2015, 2016; Maurice et al., 2015).

Qualitative VNIR spectral interpretation allows identification of one or two minerals present in mineral mixtures/ common rock samples, however, comparison with XRD analysis reveals that: 1) most samples are made of a much more complex mineral assemblage than inferred from VNIR data alone, and 2) the spectrally dominant mineral is not necessarily the most abundant. An example is given in figure 8 and table 3 that presents the comparison between the results of the VNIR spectral analyses (spectrally dominant mineral, 8a) and the Raman (figure 8b) and XRD analyses (most abundant mineral, 8c). Sulfates generally dominate the VNIR spectra when present even though they are not necessarily the most abundant mineral: for instance in sample J2L1R2 (far margin of Salar de Laco) gypsum only represents $\sim 10 \%$ of the crystalline phase but the VNIR signature is typical of this mineral (Table 2). This is also true for samples J11L1R1 and J11L1R2 from the salar de Quisquiro margin, which are dominated by halite with 10-20\% of both gypsum and bassanite but whose spectra are dominated by gypsum absorptions. However, the lower average reflectance values, the rounded shape of the absorptions and the relative strength of the 1.4 and $1.9 \mu \mathrm{m}$ features allow us to deduce the presence of another hydrated material. In one sample of the Salar de Atacama (J1L1R4), borates appear spectrally dominant in the VNIR whereas Na-sulfates are slightly more abundant (about $40 \%$ thenardite against $23 \%$ pinnoite + ulexite), nevertheless this sample contains $\sim 50 \%$ amorphous material that could also contribute to the spectral signature. In contrast anhydrous minerals such as feldspar, or anhydrous chlorides, such as halite, are more difficult to identify with VNIR or Raman spectroscopy that are more sensitive to minerals having $\mathrm{H}_{2} \mathrm{O}, \mathrm{OH}, \mathrm{CO}_{3}, \mathrm{SO}_{4}$ or $\mathrm{ClO}_{4}$ in their structure such as clays or sulfates. Although halite is more abundant in most samples from the Salar de Atacama (e.g., J11L1R2, J9L1R5, J7L4, J2L2R4, J2L2R2), the VNIR spectra are often dominated by clays and/or sulfates which are present as impurities or very minor phases. XRD 
analysis and Raman spectroscopy also detected carbonates in multiple samples (Salar de Laco J2L1R2, Laguna Tuyajto J2L2R2, Salar de Atacama J7L4, J9L1R1, J9L1R4) that were almost never detected in the VNIR data in our study when mixed with sulfates. Spectra of anhydrous carbonates exhibit strong absorptions near 2.3, 2.5, 3.4 and $3.9 \mu \mathrm{m}$, but these features become weakened for hydrous carbonates (Bishop et al., 2013), and the IR domain was not fully covered in our study. One caveat of the XRD analysis we performed is the absence of information on amorphous phases, which are minor in the samples we collected but could contribute to spectral features in the VNIR. Additionally, the semi-quantitative XRD technique used in the present study is not adapted for the characterization of clay minerals, which have been identified from morphologic observations in the clay- playa and some of the salar margins. Clays have been detected in VNIR spectra, however, they appear often mixed with sulfates, which can mask their signature if less than $30 \%$ abundance (Stack and Milliken, 2011). Therefore, although VNIR spectroscopy represents a powerful tool to distinguish between different types of terrains, deriving detailed mineralogy for complex samples as in this study is difficult with only VNIR spectra as some minerals, especially sulfates, can dominate the spectra even if present at low abundances. A suite of instruments / analyses is required to fully characterize complex mineral assemblages, and used together, VNIR spectroscopy and XRD analyses provided a powerful tool to distinguish different types of well-crystallized salt crusts.

\subsection{Correlation between spaceborne and ground data}

Multiple zones are observed within the salars on the Landsat 8 RGB composite of three different bands (Figure 2a). Each colored zone was visited in the field and outcrops were classified into multiple types based on their morphology (section 3.2). There is a good agreement in general between the various zones as mapped from space and the field observations in terms of: 1) crust types, as assigned from morphological observations and 2) mineralogy, as determined from VNIR, Raman, and XRD analysis. To the first order, field observations in terms of morphologies correlate to mineralogy derived from VNIR and XRD analyses. The type 1 crust, as observed in the central part of the Salar de Atacama, is made of $>90 \%$ halite that may contain traces of detrital material (clays, feldspar, quartz) and dry sulfates (thenardite, anhydrite). Nearly pure halite is observed in wetter areas, which appear whiter on the Landsat RGB composite (Figure 2a), and exhibit large scale 
polygons. The type 2 crust, as observed in the center part of Laguna Tuyajjto, is also a wet crust that exhibits polygons and is made of $80 \%$ halite and $20 \%$ gypsum (dark orange on Landsat RGB composite (Figure 2a)). Sulfates such as gypsum, glauberite, mirabillite are found in greater abundance in wetter areas where the Type 4 crust is observed, and correspond to brown to orangetoned terrains on Figure 2a. Type 4 crusts appear to be formed in wetter areas and near water ponds at margins or around small-scale lagoons located within the Salar de Atacama (e.g; Laguna de Cejar). Type 4 crusts display a highly variable mineralogy and variable color-tones at the meter scale, with ponds more enriched in halite or gypsum or Na-sulfates. Type 3 crusts are also characterized by multiple mineral assemblages, but are often dominated by gypsum or anhydrite mixed with detrital material. There are found mostly in marginal and dry areas, where salts are formed by efflorescence (white to yellow tones on Landsat RGB, Figure 2a). Type 3 and 4 crusts are more consistently found where the Landsat 8 sulfate parameter (Figure $2 c$ ) has higher values. Type 5 terrains (clay playas) are mapped as gray tones on the Landsat RGB composite (Figure 2a) and correspond to dry, marginal areas where the higher proportions of amorphous and clay material are detected.

Combining field and laboratory observations, however, reveal some observational bias: sulfate crusts were generally found to be thin $(<5 \mathrm{~cm})$ with a sharp transition to the underlying clay, silt, or sandrich alluvial deposits that cannot be observed from space. Therefore, even though clays and carbonates are almost always observed at shallow depths below salt crusts in the central part of the salars, and are morphologically identified in marginal areas under a thin salt efflorescence $(<1 \mathrm{~mm})$, they are very difficult to detect without digging. Drilling also allowed the identification of a former, $1 \mathrm{~cm}$-thick calcite-rich crust that was observed at $20 \mathrm{~cm}$ depth in the Salar de Laco, confirming the hypothesis derived from airborne images that this salar must have been occupied by a more alkaline lake in the past. The only exception to thin crusts lies within the Salar de Atacama where the lower limit of the hard (halite) crust was not observed, but is estimated to be at least a few meters deep. Therefore, although multispectral imagery such as Landsat represents a powerful tool to map largescale mineralogy variations in desert areas, it presents limitations regarding the vertical extent of salt 
crusts that can be thin and provides little information on the nature of the underlying material in regions with no active erosion or continuous precipitation, such as playa lakes.

\subsection{Mineralogy of Chilean salars}

Mineralogic zonation (large scale horizontal heterogeneities) was observed within most salars from both spaceborne and field analyses. Whereas the central part of the salars is occupied by highly crystalline salt crusts, made of halite and/or gypsum, margins are characterized by a higher concentration of detrital material, carbonates and clays. Halite and gypsum are detected at most margins where they form efflorescent salts deposited in the capillary fringe. Combining geochemical and flow modelling, previous hydrology studies in the Salar de Atacama have shown that meteoric water infiltrated from elevated areas in the Andes is transported to the Atacama basin where it drains laterally from east to west (Risacher et al., 2003, Vasquez et al., 2013). Where groundwater reaches the surface, discharged aquifers form lagoons or playa. Evaporation can only occur where water is available and is, therefore, concentrated around the margins of the salar (Houston, 2006). As clays, carbonates, sulfates, and chlorides precipitate, the remaining brines become more saline with minor discharges occurring by evaporation. Mineral precipitation is responsible for a strong reduction in permeability in the salt flat nucleus associated with halite and calcite formation and could explain the unique preservation of the thick halite crust (Vasquez et al., 2013).

Additionally, distinct mineral assemblages have been identified within the various salars. Possible causes of these differences include: 1) the presence of water, near or, at the surface, 2) the nature of the bedrock, 3) the composition of the feeding brines, 4) the dimension of the basin/salar, and 5) the temperature and evaporation rate. The environmental parameters (temperature, evaporation rate) do not differ much for the investigated salars. Temperature and evaporation are slightly higher in the Salar de Atacama compared to the Andean salars which are exposed to similar conditions (Table 1). Whereas the Andean salars are emplaced on a volcanic bedrock, the Salar de Atacama, a much larger salt flat, is emplaced on sedimentary bedrock. A previous survey by Risacher et al. (2003) showed that bedrock composition can partially explain the nature of the various brines involved in salt flat formation. Brines in the Atacama were found to be either sulfate-rich or calcium-rich, near-neutral or 
slightly acidic brines. Alkaline brines are almost completely lacking from the area due to the presence of gypsum-rich desert dust and the oxidation of native sulfur, whose dissolution results in brine acidification. Theoretically, $\mathrm{SO}_{4}$-rich inflow waters and their derived $\mathrm{SO}_{4}$-rich brines should be found in the intravolcanic basins of the Andes because of the nature of the bedrock and ubiquity of native sulfur. Previous workers (e.g., Risacher et al., 2013) have shown, however, that some of the Andean salars (e.g., Salar de Quisquiro) belong to the Ca-rich brines group, or mixed brines group (e.g., Salar de Aguas Calientes 3), which may indicate the presence of older sedimentary formations at depth. Ca-rich brines generally prevail in sedimentary basins of lower elevation, where Ca-rich minerals are abundant, although it appears that the Salar de Atacama, which should belong to this category, is fed by two different sources of $\mathrm{Ca}$ (to the west) and $\mathrm{SO}_{4}$ (to the east) and is, therefore, classified as formed from mixed brines (Risacher et al., 2003). Water undergoing evaporative concentration should precipitate a sequence of minerals in order of increasing solubility, starting with calcite and $\mathrm{Mg}$ - carbonates and silicates (Hardie and Eugster, 1970) followed by gypsum. Gypsum induces a new divide of the neutral path producing either $\mathrm{Ca}$-rich/$/ \mathrm{SO}_{4}$-poor or $\mathrm{SO}_{4}$-rich/Capoor waters, according to the $\mathrm{Ca} / \mathrm{SO}_{4}$ ratio at the beginning of gypsum saturation (Risacher et al., 2003). A few cases of extreme acidification, leading to acid-sulfate brines, due to hydrothermal processes and enriched sulfur contents have been reported in Chile (Salars de Gorbea and Ignorado) and Australia (e.g., McArthur et al., 1991; Long et al., 1992; Risacher et al., 2002) and might be relevant to Mars (cf. next section), but these are not observed in the salars of our study area. In their final stage, $\mathrm{SO}_{4}$-rich brines should precipitate a mixture of $\mathrm{Na} / \mathrm{Ca}$-sulfates and halite whereas $\mathrm{Ca}$-rich brines are more likely to precipitate chlorides (Hardie and Eugster, 1970; Risacher et al., 2003).

A thick, ancient halite crust was only observed in the field in the Salar de Atacama and the presence of a possibly active halite crust was inferred from spaceborne imagery in the Salar de Quisquiro, Salar de Aguas Calientes 1 and 2 and Salar de Capur, which are all derived from Ca-rich brines. No halite thick crust was observed in the salars derived from $\mathrm{SO}_{4}$-rich brines, although halite is present as a mixed component in the rock samples. The presence of a halite-dominated crust could be related to the nature of the brines, although as halite is rapidly dissolved and most brines are unsaturated, its 
formation and preservation might also depend on evaporation rates and permeability. The unique setting of the Salar de Atacama downslope from the Andean salars and its higher aridity could also explain the thickness of its halite crust that could have precipitated and accumulated from the chloride salts previously dissolved in the Andean salars. Alternatively the larger size of the salar (correlated with a higher basin size, table 1) could also somehow account for this unique, thick halite crust.

Whereas gypsum has been detected in all salars, a greater mineral diversity, including Na-rich sulfates and borates, was found at Laguna Tuyajto and Laguna Chaxa/ Laguna de Cejar/ Laguna de la Piedra, which all appear to be derived from $\mathrm{SO}_{4}$-rich brines. A greater diversity is also observed in wetter areas that are often colonized by life forms including sulfur-reducing bacteria (e.g., Stivaletta et al., 2012). Therefore, the nature of the brine and soil wetness, among other factors, ultimately influenced the final mineral assemblage as observed in the salt flats.

\subsection{Relevance to Mars}

A variety of hydrated minerals have been detected on Mars, including clays, carbonates, sulfates, and Cl salts (e.g., Poulet et al., 2005; Bibring et al., 2006; Osterloo et al., 2008,2010; Murchie et al.,2009; Ehlmann et al., 2011; Carter et al., 2010, 2013). Whereas clays are commonly detected in the ancient, Noachian (>3.7 Gy) highlands, the distribution of chloride, sulfate, and carbonatebearing materials on Mars is not as pervasive (e.g., Bibring et al., 2006; Carter et al., 2013). Mg, Fe and Ca-rich carbonates have been detected at a few locations of the surface in association with exhumed, Noachian crustal, altered rocks (Ehlmann et al., 2008, Michalski et al., 2010, Bultel et al., 2015, Wray et al., 2016), but not in lake or playa contexts. Proposed chloride-bearing materials are identified based on their spectral distinctiveness in the TIR images and association with light-toned, indurated, fractured material often found in topographic lows (Osterloo et al., 2008, 2010, Glotch et al., 2010, Figure 9c,d), and draped on both Noachian and Hesperian (3.7 - 3.0 Gy) units. Based on their context and the existence of fractures and polygonal textures, proposed chloride-bearing materials have been inferred to originate from both ponding of surface runoff, and groundwater upwellings, followed by evaporation (Osterloo et al., 2010). $\mathrm{Mg}, \mathrm{Fe}$ and sometimes Ca-sulfates are 
commonly detected in association with kilometer-thick Hesperian layered deposits (e.g., Gendrin et al., 2005; Flahaut et al., 2010, 2014, 2015) and polar dunes (Langevin et al., 2005, Massé et al., 2010), although more localized detections were also reported (e.g., Wray et al., 2011, Loizeau et al., 2015, Figure 9b). Although their origin is debated, the morphology and mineralogy of some sulfate salts (e.g., sulfate-rich depostis in Meridiani Planum), and their distribution in regions where groundwater upwellings are predicted, is consistent with an evaporitic origin (e.g., Ardvison et al., 2005; Andrews-Hanna et al., 2007; Osterloo et al., 2010, Davila et al., 2011, Flahaut et al., 2015). The observation of karstic features such as dolines, ridges and pans in the etched terrains of Meridiani Planum region supports the groundwater hypothesis and points to the existence of martian sulfate-rich salars locally (Baioni et al., 2013, Flahaut et al., 2015, Figure 9a). Both sulfates and high levels of $\mathrm{Cl}$ (which could be attributed to chlorides) were detected in situ by the Opportunity Rover in the hematite plains of Meridiani Planum, which lies directly above the etched terrains unit (Ardvison et al., 2006; Squyres et al., 2006).

Therefore, some of the processes involved in the formation of the Chilean salars are likely to be active or have been active on Mars. This study also employed similar spectroscopic wavelength ranges and resolutions to those used by orbiting instruments to examine Martian mineralogy. From our observations we can infer that horizontal and vertical zonation is expected in the martian salars and could be observed, providing that we have enough spatial resolution. Landsat imagery $(\sim 30 \mathrm{~m} / \mathrm{px})$ has a similar ground pixel size as the MRO/CRISM instrument ( 20m/px) which should be able to capture horizontal features. Landsat spectral resolution is far less, but sufficient to distinguish between various salt crusts providing promising results for multispectral cameras such as PanCam on the ExoMars rover (Griffiths et al., 2006). The high resolution of VNIR Instruments such as Micromega and ISEM (Pilorget and Bibring, 2013; Korablev et al., 2015, 2016) should distinguish between various types of salts and salt crusts on Mars, but could meet the same difficulties we evidenced with the ASDinc Fieldspec measurements in the case of mixtures. XRD analyses have been performed on the Curiosity Rover in an attempt to quantify mineralogic assemblages, with two major caveats: 1) the rover can only perform disoriented preparations which are not well-suited for clay identification, 2) the rover 
analyzed samples containing up to 50\% amorphous materials (Morris et al;, 2015) that could not be characterized by XRD techniques (but could potentially be identified by VNIR techniques). Martian VNIR data sets also have a higher degree of noise that our Atacama spectra because of the contribution of atmospheric $\mathrm{CO}_{2}$, aerosols and dust.

A climate-change related lacustrine to playa transition over time has also been suggested for Mars and is well documented at the Salar de Laco, where evidence for a former alkaline lake is found in the field (sampled calcite crust at a $20 \mathrm{~cm}$ depth) and also in spaceborne images (presence of paleoshores). The composition of martian bedrock is likely to be more basaltic than the andesitic Andean highlands, resulting in more Fe/Mg-rich brines and minerals, but similar complex evaporitic sequences and mineral assemblages are expected, with possible variations from one site to another. A major issue is whether these assemblages can be determined from VNIR surface spectroscopy solely given that in the presence of hydrated sulfates, a wide range of minerals can be masked (e.g., clays, carbonates, felsic and mafic minerals). In addition, given that carbonates are the first to precipitate from an evaporitic sequence, they are likely to concentrate at the margins and bottom of the salars and be subject to burial. As shown here and in recent studies (e.g., Hanley, 2015, Lynch, 2015), it might be complicated to distinguish some hydrated chloride salts and hydrated chlorine oxyanion salts from sulfate salts, making martian sulfate detections potentially debatable. For instance, Na-rich sulfates and chlorides are expected to precipitate alongside with Mg-rich sulfates from $\mathrm{MgSO}_{4}$-rich brines on Mars, but they have yet to be detected in the km-thick interior layered deposits of Valles Marineris or the etched terrains deposits of Meridiani Planum. However a recent study from Wang et al. (2016) interprets the presence of monohydrated Mg-sulfates at the bottom of the layered deposits as indicative of the presence of associated chlorides and Na-rich sulfates that would help overcome the metastability of starkeyite (polyhydrated Mg-sulfates); starkeyite being only detected at higher elevations (e.g., Fueten et al., 2014, Noel et al., 2015). Determining the exact mineral assemblages on Mars is key to characterizing past Martian surface chemistry, which should benefit in the coming decades by the development of spectral libraries (that are still incomplete for sulfates and chlorides) and the study of the spectral properties of lab mixtures and analog rock samples. 
In addition, combining VNIR spectroscopic data with other datasets can aid with inferring the context and sometimes the mineralogy if certain characteristic patterns are present. For instance, ElMaarry et al. (2015) noticed that desiccation fractures are especially present in clay and chloride-rich deposits formed from evaporation. We concur with this from our field observations and further noticed that larger scale polygons are present in chloride deposits compared to clay deposits. The texture of the crust as observed in the Atacama salars was also found to be related to its dominant mineralogy and formation mechanism (efflorescence versus precipitation). Finally, in the Atacama salar there is a strong relationship between the dominant mineralogy and the albedo (higher for sulfate-rich area, and lower for clay-rich playas) of the deposits as seen from space, with the exception of unfrequently flooded, dust-covered crusts being darkened.

Understanding the formation of martian salts is also key to providing insight into the planet's habitability. Evidence for biomaterials is present in the VNIR data (e.g., chlorophyll absorption at 0.68 microns at Laguna Tuyajto J2L2R2 and Laguna de la Piedra J9L2R3), Raman data (carotenoid peaks in Laguna Tuyajto sample J2L2R3 and Salar de Quisquiro J11L1R1) and XRD data (presence of pigments in several samples, including Laguna Tuyajto J2L2R3 and Laguna de la Piedra J9L2R2) described above. A complementary survey carried out by Monaghan et al. (in prep.) aims to determine the type of organisms that thrive in the Atacama extreme environments and study their dependence on the mineralogy among other factors. Although perchlorates were not directly detected in our samples, they have been reported at other locations of the Atacama desert and on Mars (e.g., Catling et al., 2010) and could play a role in the development of life and biosignature preservation.

\section{Conclusions}

We performed a coordinated remote sensing and field survey of the Chilean Atacama salars, which were studied with various techniques (VNIR reflectance and Raman spectroscopy, morphologic analyses, XRD analysis). Remote sensing and field observations, as well as observations made with various techniques led to consistent results. Although VNIR analyses proved to be an efficient firstorder, quick and nondestructive tool for mineralogic investigation, XRD analyses in the lab provided 
more complete information on assemblages, especially those that are spectrally dominated by sulfate signatures, which can mask the presence of other minerals (clays, chlorides, carbonates, feldspar).

Landsat multispectral imagery was used to map mineral zones that are easily identified in the absence of vegetation, and because most units are homogenous on large-scales. Both orbital and field data show that the formation mechanism of the salar through groundwater evaporation at topographic breaks in lowlands result in horizontal (margin vs. center) and vertical (salt crust at the surface) zonation. Clays, carbonates and detritic material are found at the margins of the salars and at depth, whereas salt-rich crust (halite and/or Ca-sulfates) form at their centers. A variability of Narich sulfates and borates are also present near wet areas. The nature of the salt crusts vary between the different salars and appear to be a function of the local bedrock but also brine chemistry and wetness. Similar processes are expected on Mars, where salars have been previously reported, although more acidic/ Mg-rich brines are expected and should result in slightly different mineral assemblages.

\section{Acknowledgments}

The authors are grateful to all of those who made this project and the field excursion possible, especially our local guide Mathilde Monseu, our astrobiologist partners Pascale Ehrenfreund, Euan Monaghan and Simone Martini at Leiden University, Andreas Kaufer at ESO and Bernard Foing at ESA, who provided us with logistical support. Our team was hosted by the wonderful APEX staff at the Sequitor base camp near San Pedro de Atacama; to Felipe, Carlos, Karl, Paulina, Francisco, Thomas, Luis, Pablo and others: many many thanks for your warm welcome, your support and making this visit so unforgettable! We will see you again in the Atacama! The field VNIR spectra were collected with an ASDinc FieldSpec 4 that was generously loaned to N.J Potts through the 2015 Goetz Instrument Support Program. We are particularly grateful to Tom Ulrich at ASDinc for his support regarding our research project. The authors are also thankful to all the data instrument teams: Landsat, ASTER (The ASTER GDEM is a product of METI and NASA), DigitalGlobe, CTX and the Earth Explorer and USGS L8SR web services. The Context Camera (CTX) images are generously made available by the team on the Planetary Data System (PDS) archive and were 
processed using the e-mars web application (emars.univ-lyon1.fr). The author would like to thank the e-mars team including C. Quantin and L. Lozach for their help. The authors would also like to thank Ruben Vera and the XRD facility at the Centre de Diffractométrie Henri Longchambon of the University Lyon 1 (France) for their valuable advice and support during and after the XRD analyses. Raman analyses were performed at the Raman laboratory of the Vrije University Amsterdam with the help of Freek Ariese and Roel van Elsas for sample preparation. The campaign was funded by a Netherlands Organisation for Scientific Research (N.W.O.) VENI Innovational Research grant attributed to J. Flahaut. Additional support to J. Bishop from the NASA Astrobiology Institute is appreciated. Finally the authors would like to thank the editor and two anonymous reviewers for their valuable comments that helped improve the manuscript. Sample material and spectral data can be made available on a simple request to the first author, pending availability.

\section{References}

Amos, B. J. and D. Greenbaum, 1987. Alteration detection using TM imagery: the effects of supergene weathering in an arid climate. ERIM, 21th Int. Sym. on Remote Sensing of Environment. Oct. 26-30, Ann Arbor, Michigan, USA : 795.

Andrews-Hanna, J.C., Phillips, R.J., Zuber, M.T., 2007. Meridiani Planum and the global hydrology of Mars. Nature 446 (7132), 163-166.

Arvidson, R.E. et al., 2005. Spectral reflectance and morphologic correlations in eastern Terra Meridiani, Mars. Science 307 (5715), 1591-1594.

Arvidson, R.E. et al., 2006. Nature and origin of the hematite-bearing plains of Terra Meridiani based on analyses of orbital and Mars Exploration Rover data sets. J. Geophys. Res. 111, E12S08. http://dx.doi.org/10.1029/2006JE002728.

Armijo, R., Lacassin, R., Coudurier-Curveur, A. and Carrizo, D., 2015. Coupled tectonic evolution of Andean orogeny and global climate. Earth-Science Reviews, 143, pp.1-35. 
Baioni, D., Sgavetti, M., 2013. Karst terrains as possible lithologic and stratigraphic markers in northern Sinus Meridiani, Mars. Planet. Space Sci. 75, 173-181. http://dx.doi.org/10.1016/j.pss.2012.08.011.

Bao, H., Jenkins, K.A., Khachaturyan, M. and Díaz, G.C., 2004. Different sulfate sources and their post-depositional migration in Atacama soils. Earth and Planetary Science Letters, 224(3), pp.577587.

Berger, I.A. and Cooke, R.U., 1998. The origin and distribution of salts on alluvial fans in the Atacama Desert, northern Chile. Earth Surface Processes and Landforms, 22(6), pp.581-600.

Bibring, J.-P. et al., 2004. OMEGA: Observatoire pour la minéralogie, l'eau, les glaces et l'activité, ESA-SP, p. 1240.

Bibring, J.-P. et al., 2006. Global mineralogical aqueous mars history derived from OMEGA/Mars Express Data. Science 312, 400-404. http://dx.doi.org/10.1126/ science.1122659.

Bishop, J.L., Lane, M.D., Dyar, M.D., Brown, A.J., 2008. Reflectance and emission spectroscopy of four groups of phyllosilicates: Smectites, kaolinite-serpentines, chlorites, and micas. Clay Miner. 43, 35-54. http://dx.doi.org/10.1180/ claymin.2008.043.1.03.

Bishop, J.L. et al., 2009. Mineralogy of Juventae Chasma: Sulfates in the light-toned mounds, mafics in the sand, and opal in the plains. J. Geophys. Res. 114, E00D09. http://dx.doi.org/10.1029/2009JE003352.

Bishop, J.L., Perry, K.A., Darby Dyar, M., Bristow, T.F., Blake, D.F., Brown, A.J. and Peel, S.E., 2013. Coordinated spectral and XRD analyses of magnesite-nontronite-forsterite mixtures and implications for carbonates on Mars. Journal of Geophysical Research: Planets, 118(4), pp.635-650.

Bishop, J. L., Lane, M. D., Dyar, M. D., King, S. J., Brown, A. J., Swayze, G., 2014a. Spectral properties of Ca-sulfates: Gypsum, bassanite and anhydrite. American Mineralogist. 99, 2105-2115. 
Bishop, J. L., Quinn, R. C., Dyar, M. D., 2014b. Spectral and thermal properties of perchlorate salts and implications for Mars. American Mineralogist. 99, 1580-1592.

Bishop, J.L., Ward, M.K., Roush, T.L., Davila, A., Brown, A.J., McKay, C.P., Quinn, R. and Pollard, W., 2014c. Spectral properties of Na, Ca-, Mg-and Fe-chlorides and analyses of hydrohalitebearing samples from Axel Heiberg Island. In Lunar Planet. Sci. Conf (Vol. 45).

Bultel, B., C. Quantin-Naraf, M. Andréani, H. Clénet, and L. Lozac'h, 2015. Deep alteration between Hellas and Isidis basins, Icarus, 260, 141-160, doi:10.1016/j.icarus.2015.06.037.

Caracas, R., \& Bobocioiu, E., 2011. The WURM project—a freely available web-based repository of computed physical data for minerals. American Mineralogist, 96(2-3), 437-443.

Carr, M.H., Head III, J.W., 2010. Geologic history of Mars. Earth Planet. Sci. Lett. 294 (3-4), 185203. http://dx.doi.org/10.1016/j.eps1.2009.06.042.

Carter, J., Poulet, F., Bibring, J.-P., Murchie, S., 2010. Detection of hydrated silicates in crustal outcrops in the Northern Plains of Mars. Science 328 (5986), 1682-1686. http://dx.doi.org/10.1126/science.1189013.

Carter, J., Poulet, F., Bibring, J.-P., Mangold, N., Murchie, S., 2013. Hydrous minerals on Mars as seen by the CRISM and OMEGA imaging spectrometers: Updated global view. J. Geophys. Res. Planets 118, 831-858. http://dx.doi.org/10.1029/ 2012JE004145

Catling, D.C., Claire, M.W., Zahnle, K.J., Quinn, R.C., Clark, B.C., Hecht, M.H. and Kounaves, S., 2010. Atmospheric origins of perchlorate on Mars and in the Atacama. Journal of Geophysical Research: Planets, 115(E1).

Chapman, J. E., Rothery, D. A., Francis, P. W., \& Pontual, A., 1989. Remote sensing of evaporite mineral zonation in salt flats (salars). Remote Sensing,10(1), 245-255.

Clark, R.N. et al., 1990. High resolution reflectance spectroscopy of minerals. J. Geophys. Res. 95 (B8), 12653-12680. 
Clark, R.N. et al., 2007. USGS Digital Spectral Library splib06a. U.S. Geological Survey, Digital Data Series, p. 231.

Cloutis, E.A. et al., 2006. Detection and discrimination of sulfate minerals using reflectance spectroscopy. Icarus 184, 121-157.

Cloutis, E., Berg, B., Mann, P. and Applin, D., 2016. Reflectance spectroscopy of low atomic weight and Na-rich minerals: Borates, hydroxides, nitrates, nitrites, and peroxides. Icarus, 264, pp.20-36.

Crowley, J.K., 1990. A spectral reflectance study $(0.4-2.5 \mu \mathrm{m})$ of selected playa evaporite mineral deposits and related geochemical processes. In 10th Annual International Geoscience and Remote Sensing Symposium-IGARSS'90 (Vol. 2, p. 965).

Davila, A. et al., 2011. A large sedimentary basin in the Terra Sirenum region of the southern highlands of Mars, Icarus, 212, 2, 579-589, doi:10.1016/j.icarus.2010.12.023.

De Angelis, S., De Sanctis, M.C., Ammannito, E., Di Iorio, T., Carli, C., Frigeri, A., Capria, M.T., Federico, C., Boccaccini, A., Capaccioni, F. and Giardino, M., 2014. VNIR spectroscopy of Mars analogues with the ExoMars-MaMiss instrument. MSAIS, 26, p.121.

Dingman, R., 1962. Tertiary salt domes near San Pedro de Atacama. Chile. US Gcol. Sun., Praf. Pap, (4S), pp.92-94.

Dingman, R.J., 1967. Geology and ground-water resources of the northern part of the Salar de Atacama, Antofagasta Province, Chile (No. 1219). US Govt. Print. Off.

Drake, N.A., 1995. Reflectance spectra of evaporite minerals (400-2500 nm): applications for remote sensing. International Journal of Remote Sensing, 16(14), pp.2555-2571.

Downs, R.T. and Hall-Wallace, M., 2003. The American Mineralogist Crystal Structure Database. American Mineralogist 88, 247-250.

Ehlmann, B. L., et al., 2008. Orbital identification of carbonate-bearing rocks on Mars, Science, 322, 1828-1832, doi:10.1126/science.1164759. 
Ehlmann, B.L. et al., 2009. Identification of hydrated silicate minerals on Mars using MROCRISM:

Geologic context near Nili Fossae and implications for aqueous alteration. J. Geophys. Res. 114, E00D08. http://dx.doi.org/10.1029/ 2009JE003339.

Ehlmann, B.L. et al., 2011. Subsurface water and clay mineral formation during the early history of Mars. Nature 479, 53-60. http://dx.doi.org/10.1038/nature10582.

El-Maarry, M.R., Watters, W.A., Yoldi, Z., Pommerol, A., Fischer, D., Eggenberger, U. and Thomas, N., 2015. Field investigation of dried lakes in western United States as an analogue to desiccation fractures on Mars. Journal of Geophysical Research: Planets, 120(12), pp.2241-2257.

Epema, G. F., 1986. Processing thematic mapper data for mapping in Tunisia. ITC Journal, $1: 30$ 34.

Epema, G. F., 1990. Effect of moisture content on spectral reflectance in a playa area in southem tunisia. Proceedings of the Int. Symp. on Remote Sensing Water Ressources. IAH, august 20-24, Enschede, The Netherlands : 301-308.

Ericksen, G.E., 1981. Geology and the origin of the Chilean nitrate deposits, Geol. Soc. Amer. Spec. Paper, 1188 (1981), p. 37.

Ericksen, G.E., 1983. The Chilean Nitrate Deposits: The origin of the Chilean nitrate deposits, which contain a unique group of saline minerals, has provoked lively discussion for more than 100 years. American Scientist, 71(4), pp.366-374.

Fassett, C.I. and Head, J.W., 2008. Valley network-fed, open-basin lakes on Mars: Distribution and implications for Noachian surface and subsurface hydrology. Icarus, 198(1), pp.37-56.

Flahaut, J., C. Quantin, P. Allemand, P. Thomas, and L. Le Deit, 2010. Identification, distribution and possible origins of sulfates in Capri Chasma (Mars), inferred from CRISM data, J. Geophys. Res., 115, E11007,doi:10.1029/2009JE003566. 
Flahaut, J., Massé, M., Le Deit, L., Thollot, P., Bibring, J.P., Poulet, F., Quantin, C., Mangold, N., Michalski, J. and Bishop, J.L., 2014. Sulfate-Rich Deposits on Mars: A Review of Their Occurences and Geochemical Implications. LPI Contributions, 1791, p.1196.

Flahaut, J., J. Carter, F. Poulet, J.-P. Bibring, W. van Westrenen, G.R. Davies, S.L. Murchie (2015), Embedded clays and sulfates in Meridiani Planum, Mars, Icarus, 248, 269-288, doi:10.1016/j.icarus.2014.10.046.

Fueten, F., Flahaut, J., Stesky, R., Hauber, E. and Rossi, A.P., 2014. Stratigraphy and mineralogy of Candor Mensa, West Candor Chasma, Mars: insights into the geologic history of Valles Marineris. Journal of Geophysical Research, 119, pp.1-24.

Irons, J.R., J.L. Dwyer, J.A. Barsi, 2012. The next Landsat satellite: The Landsat Data Continuity Mission Remote Sensing of Environment, 122, pp. 11-21.

Gaffey, S.J., 1986. Spectral reflectance of carbonate minerals in the visible and near infrared (O. 352.55 microns); calcite, aragonite, and dolomite. American Mineralogist, 71(1-2), pp.151-162.

Gendrin, A. et al., 2005. Sulfates in martian layered terrains: The OMEGA/Mars Express view. Science 307, 1587-1591.

Glotch, T. D., Bandfield, J. L., Tornabene, L. L., Jensen, H. B., \& Seelos, F. P., 2010. Distribution and formation of chlorides and phyllosilicates in Terra Sirenum, Mars. Geophysical Research Letters, 37(16).

Goodall, T.M., North, C.P. and Glennie, K.W., 2000. Surface and subsurface sedimentary structures produced by salt crusts. Sedimentology, 47(1), pp.99-118.

Gražulis, S. et al., 2009. Crystallography Open Database-an open-access collection of crystal structures. Journal of Applied Crystallography, 42(4), 726-729. 
Griffiths, A.D., Coates, A.J., Jaumann, R., Michaelis, H., Paar, G., Barnes, D. and Josset, J.L., 2006. Context for the ESA ExoMars rover: the Panoramic Camera (PanCam) instrument. International Journal of Astrobiology, 5(03), pp.269-275.

Hanley, J., Dalton, J.B., Chevrier, V.F., Jamieson, C.S. and Barrows, R.S., 2014. Reflectance spectra of hydrated chlorine salts: The effect of temperature with implications for Europa. Journal of Geophysical Research: Planets, 119(11), pp.2370-2377.

Hanley, J., Chevrier, V.F., Barrows, R.S., Swaffer, C. and Altheide, T.S., 2015. Near-and mid-infrared reflectance spectra of hydrated oxychlorine salts with implications for Mars. Journal of Geophysical Research: Planets, 120(8), pp.1415-1426.

Hooijschuur, J. H., Verkaaik, M. F. C., Davies, G. R. \& Ariese, F., 2015. Will Raman meet bacteria on Mars? An overview of the optimal Raman spectroscopic techniques for carotenoid biomarkers detection on mineral backgrounds. Neth. J. Geosci. DOI: 10.1017/njg.2015.3

Hardie, L.A. and Eugster, H.P., 1970. The evolution of closed-basin brines. Mineralogical Society of America Special Publication, 3, pp.273-290.

Houston, J. and Hartley, A.J., 2003. The central Andean west-slope rainshadow and its potential contribution to the origin of hyper-aridity in the Atacama Desert. International Journal of Climatology, 23(12), pp.1453-1464.

Houston, J., 2006. Evaporation in the Atacama Desert: An empirical study of spatio-temporal variations and their causes. Journal of Hydrology, 330(3), pp.402-412.

Hunt, G.R., Salisbury, J.W., 1970. Visible and near infrared spectra of minerals and rocks. Mod. Geol. 1, 283-300.

Hynek, B.M., Beach, M. and Hoke, M.R., 2010. Updated global map of Martian valley networks and implications for climate and hydrologic processes. Journal of Geophysical Research: Planets, 115(E9). 
Kabekkodu, S. N., Faber, J., \& Fawcett, T., 2002. New Powder Diffraction File (PDF-4) in relational database format: advantages and data-mining capabilities. Acta Crystallographica Section B: Structural Science, 58(3), 333-337.

Korablev, O. et al., 2015. Development of a mast or robotic arm-mounted infrared AOTF spectrometer for surface Moon and Mars probes, Proc. of SPIE Vol. 9608 960807-1.

Korablev, O. et al. 2016. Infrared Spectrometer for ExoMars (ISEM), a mast mounted instrument for the rover. Under reviews at Astrobiology.

Langevin, Y., Poulet, F., Bibring, J.P. and Gondet, B., 2005. Sulfates in the north polar region of Mars detected by OMEGA/Mars Express. Science, 307(5715), pp.1584-1586.

Loizeau, D., Mangold, N., Poulet, F., Bibring, J.P., Bishop, J.L., Michalski, J. and Quantin, C., 2015. History of the clay-rich unit at Mawrth Vallis, Mars: High-resolution mapping of a candidate landing site. Journal of Geophysical Research: Planets, 120(11), pp.1820-1846.

Long, D.T., Fegan, N.E., McKee, J.D., Lyons, W.B., Hines, M.E. and Macumber, P.G., 1992. Formation of alunite, jarosite and hydrous iron oxides in a hypersaline system: Lake Tyrrell, Victoria, Australia. Chemical Geology, 96(1), pp.183-202.

Lynch, K.L., Horgan, B.H., Munakata-Marr, J., Hanley, J., Schneider, R.J., Rey, K.A., Spear, J.R., Jackson, W.A. and Ritter, S.M., 2015. Near-infrared spectroscopy of lacustrine sediments in the Great Salt Lake Desert: An analog study for Martian paleolake basins. Journal of Geophysical Research: Planets, 120(3), pp.599-623.

Martini, S., E.P. Monaghan, J. Flahaut, M. Martinot, J.W. Aerts, I. Myrgorodska, C. Meinert, U.J. Meierhenrich, P. Ehrenfreund 2016. Biomolecule Preservation in Mars Soil Analogues, Biomarkers and Molecular Isotopes: International Workshop of Organic Geochemistry, Osaka, Japan. July 4-5. 
Massé, M., Bourgeois, O., Le Mouélic, S., Verpoorter, C., Le Deit, L. and Bibring, J.P., 2010. Martian polar and circum-polar sulfate-bearing deposits: Sublimation tills derived from the North Polar Cap. Icarus, 209(2), pp.434-451.

Maurice, S., Wiens, R.C., Le Mouélic, S., Anderson, R., Beyssac, O., Bonal, L., Clegg, S., DeFlores, L., Dromart, G., Fischer, W. and Forni, O., 2015. The SuperCam Instrument for the Mars2020 Rover. In European Planetary Science Congress 2015, Abstract \#EPSC2015-185 (Vol. 10, p. 185).

McArthur, J.M., Turner, J.V., Lyons, W.B., Osborn, A.O. and Thirlwall, M.F., 1991. Hydrochemistry on the Yilgarn Block, Western Australia: Ferrolysis and mineralisation in acidic brines. Geochimica et Cosmochimica Acta, 55(5), pp.1273-1288.

McKay, C.P., Friedmann, E.I., Gómez-Silva, B., Cáceres-Villanueva, L., Andersen, D.T. and Landheim, R., 2003. Temperature and moisture conditions for life in the extreme arid region of the Atacama Desert: four years of observations including the El Niño of 1997-1998. Astrobiology, 3(2), pp.393-406.

Michalski, G., Böhlke, J.K. and Thiemens, M., 2004. Long term atmospheric deposition as the source of nitrate and other salts in the Atacama Desert, Chile: New evidence from mass-independent oxygen isotopic compositions. Geochimica et Cosmochimica Acta, 68(20), pp.4023-4038.

Michalski, J. R., and P. B. Niles, 2010. Deep crustal carbonate rocks exposed by meteor impact on Mars, Nat. Geosci., 3, 751-755, doi:10.1038/ngeo971.

Monaghan et al., Amino acids and signs of life in Atacama desert soils, in prep.

Morris, R. V. et al. 2015. Transmission X-ray Diffraction (XRD) Patterns Relevant to the MSL Chemin Amorphous Component: Sulfates And Silicates, Lunar Planet. Sci. XLII. Abstract \#2434.

Mougenot, B., P. Zante, J. P. Montoroi, 1990. Détection et évolution saisonnière des sols salés et acidifiés du domaine jluvio-marin de basse Casamance au Sénégal par imagerie satellitaire. Télédétection et sécheresse. Paris, Aupelf-Uref, John Libbey Eurotext : 173-179. 
Mougenot, B., 1993. Effets des sels sur la réflectance et télédétection des sols salés. Cahiers ORSTOM, Serie Pedologie, 28, pp.45-54.

Murchie, S. et al., 2007. Compact reconnaissance Imaging Spectrometer for Mars (CRISM) on Mars Reconnaissance Orbiter (MRO). J. Geophys. Res. 112 (E5), E05S03. http://dx.doi.org/10.1029/2006JE002682.

Murchie, S.L. et al., 2009. A synthesis of martian aqueous mineralogy after 1 Mars year of observations from the Mars Reconnaissance Orbiter. J. Geophys. Res. 114, E00D06. http://dx.doi.org/10.1029/2009JE003342.

Navarro-González, R., Rainey, F.A., Molina, P., Bagaley, D.R., Hollen, B.J., de la Rosa, J., Small, A.M., Quinn, R.C., Grunthaner, F.J., Cáceres, L. and Gomez-Silva, B., 2003. Mars-like soils in the Atacama Desert, Chile, and the dry limit of microbial life. Science, 302(5647), pp.1018-1021.

Noel, A., Bishop, J.L., Al-Samir, M., Gross, C., Flahaut, J., McGuire, P.C., Weitz, C.M., Seelos, F. and Murchie, S., 2015. Mineralogy, morphology and stratigraphy of the light-toned interior layered deposits at Juventae Chasma. Icarus, 251, pp.315-331.

Osterloo, M. M., et al., 2008. Chloride-bearing materials in the southern highlands of Mars. Science, 319(5870), 1651-1654.

Osterloo, M. M., Anderson, F. S., Hamilton, V. E., \& Hynek, B. M., 2010. Geologic context of proposed chloride-bearing materials on Mars. Journal of Geophysical Research: Planets, 115(E10).

Piatek, J.L., Hardgrove, C., Moersch, J.E., Drake, D.M., Wyatt, M.B., Rampey, M., Carlisle, O., Warren-Rhodes, K., Dohm, J.M., Hock, A.N. and Cabrol, N.A., 2007. Surface and subsurface composition of the Life in the Atacama field sites from rover data and orbital image analysis. Journal of Geophysical Research: Biogeosciences, 112(G4).

Pieters, C.M., Boardman, J., Buratti, B., Chatterjee, A., Clark, R., Glavich, T., Green, R., Head, J., Isaacson, P., Malaret, E. and McCord, T., 2009. The Moon mineralogy mapper (M3) on Chandrayaan-1. Curr. Sci, 96(4), pp.500-505. 
Pilorget, C. and Bibring, J.P., 2013. NIR reflectance hyperspectral microscopy for planetary science: Application to the MicrOmega instrument. Planetary and Space Science, 76, pp.42-52.

Poulet, F. et al., 2005. Phyllosilicates on Mars and implications for early martian climate. Nature 438, 623-627. http://dx.doi.org/10.1038/nature04274.

Rech, J.A., Quade, J. and Hart, W.S., 2003. Isotopic evidence for the source of Ca and S in soil gypsum, anhydrite and calcite in the Atacama Desert, Chile. Geochimica et Cosmochimica Acta, 67(4), pp.575-586.

Risacher, F., H. Alonso, C. Salazar, 2002. Hydrochemistry of two adjacent acid saline lakes in the Andes of northern Chile, Chemical Geology, 187 (1-2), pp. 39-5.

Risacher, F., Alonso, H. and Salazar, C., 2003. The origin of brines and salts in Chilean salars: a hydrochemical review. Earth-Science Reviews, 63(3), pp.249-293.

Squyres, S.W. et al., 2006. Two years at Meridiani Planum: Results from the Opportunity Rover. Science 313, 1403-1407. http://dx.doi.org/10.1126/ science.1130890.

Stack, K.M., Milliken, R.E., 2011. Reflectance spectroscopy of clay-sulfate mixtures: Implications for quantifying hydrated minerals and determining depositional environments on Mars. Lunar Planet. Sci. XLII. Abstract \#2024.

Stivaletta N., Barbieri R, Billi D., 2012. Microbial colonization of the salt deposits in the driest place of the Atacama Desert (Chile), Orig Life Evol Biosph. 2012 Jun;42(2-3):187-200. doi: 10.1007/s11084-012-9289-y.

Stoertz, G. E., \& Ericksen, G. E., 1974. Geology of salars in northern Chile (No. 811). USGPO.

Sutter, B., Dalton, J.B., Ewing, S.A., Amundson, R. and McKay, C.P., 2007. Terrestrial analogs for interpretation of infrared spectra from the Martian surface and subsurface: Sulfate, nitrate, carbonate, and phyllosilicate-bearing Atacama Desert soils. Journal of Geophysical Research: Biogeosciences, $112(\mathrm{G} 4)$. 
USGS, 2015. Provisional Landsat 8 Surface Reflectance Product Guide. http://landsat.usgs.gov/documents/provisional_18sr_product_guide.pdf.

Vasquez, C., Ortiz, C., Suárez, F. and Muñoz, J.F., 2013. Modeling flow and reactive transport to explain mineral zoning in the Atacama salt flat aquifer, Chile. Journal of Hydrology, 490, pp.114125.

Verkaaik, M. F. C., Hooijschuur, J. H., Davies, G. R. \& Ariese, F., 2015. Raman spectroscopic techniques for planetary exploration: detecting microorganisms through minerals. Astrobiology 15, 697-707.

Wang, A., B. L. Jolliff, Y. Liu, and K. Connor, 2016. Setting constraints on the nature and origin of the two major hydrous sulfates on Mars: Monohydrated and polyhydrated sulfates, J. Geophys. Res. Planets, 121, 678-694, doi:10.1002/2015JE004889.

Wettergreen, D., Bapna, D., Maimone, M. and Thomas, G., 1999. Developing Nomad for robotic exploration of the Atacama Desert. Robotics and Autonomous Systems, 26(2), pp.127-148.

Wray, J.J., Milliken, R.E., Dundas, C.M., Swayze, G.A., Andrews-Hanna, J.C., Baldridge, A.M., Chojnacki, M., Bishop, J.L., Ehlmann, B.L., Murchie, S.L. and Clark, R.N., 2011. Columbus crater and other possible groundwater-fed paleolakes of Terra Sirenum, Mars. Journal of Geophysical Research: Planets, 116(E1).

Wray, J. J., S. L. Murchie, J. L. Bishop, B. L. Ehlmann, R. E. Milliken, M. B. Wilhelm, K. D. Seelos, and M. Chojnacki (2016), Orbital evidence for more widespread carbonate-bearing rocks on Mars, J. Geophys. Res. Planets, 121, 652-677, doi:10.1002/2015JE004972.

Wynne, J.J., Titus, T.N. and Diaz, G.C., 2008. On developing thermal cave detection techniques for Earth, the Moon and Mars. Earth and Planetary Science Letters, 272(1), pp.240-250. 


\section{Tables and figures captions}

Table 1: List of investigated salars and collected samples at each location. The corresponding brine types and salar properties were extracted from Risacher et al. (2003). No information were available for the Laguna Cejar, de la Piedra and Chaxa specifically, but as they are located in the eastern part of the Atacama salar, they are all inferred to be fed by mixed to SO4-rich brines.

Table 2: Summary of XRD detections for all samples. For crystallinity values, the,+++ and +++ symbols indicate the following ranges of values, respectively : $>40 \%,>60 \%,>80 \%$. For mineral abundances, the,,-+++ and +++ symbols indicate the following ranges of values, respectively : present but $<10 \%,>10 \%,>50 \%,>80 \%$. Gray lines indicate samples of lower crystallinity $(<80 \%)$. Sample names starting with A- indicate that the samples were also collected in sterile conditions for biology analyses (see Martini et al., 2016). Gyp = gypsum, Hal= halite, $\mathrm{Cal}=$ calcite, Ara $=$ aragonite, Do $=$ dolomite, Natri $=$ natrite, natro $=$ natron, $\mathrm{An}=$ anorthite, $\mathrm{Alb}=$ albite, $\mathrm{Qz}=$ quartz, $\mathrm{Bass}=$ bassanite, Anh $=$ anhydrite, Gla $=$ glauberite, $\mathrm{Blo}=$ blodite, The $=$ thenardite, Mir $=$ mirabilite, Pin $=$ pinnoite, $\mathrm{Ul}=$ ulexite, Nob = Nobleite, Sylv = Sylvite, Hydg= hydroglauberite, Hydp $=$ hydrophilite, $\mathrm{Al}=$ alunite, phyl $=$ phyllosilicates.

Table 3: Comparison of VNIR, Raman and XRD data mineralogic interpretation for a subset of representative samples, shown in figure 8 (Also see section 5.1). Gray lines indicate the set of samples which VNIR spectra are shown in figure 5. For the Raman column: N= no peaks, $\mathrm{C}=$ carotenoids.

Figure 1: a) Location of the study area (ArcGIS world imagery maps, ESRI/TerraColor), b) ASTER global digital elevation model (GDEM) of the study area. The ASTER GDEM is a product of METI and NASA. c) AB East-west Topographic profile highlighting the succession of mountain ranges (CR: Coastal Range; CD: Cordillera de Domeyko; CdlS: Cordillera de la Sal, WC: Western Cordillera) and basins/plateaus. d) Location of the sampling sites (green and red circles, red circles locations where sterile sampling was performed for astrobiological analyses (see companion paper by Monaghan et al.)), main salars (yellow outlines) and protected areas (Flamingo reserve, orange 
hatch) on DigitalGlobe 1 meter/pixel satellite imagery (ArcGIS world imagery maps, ESRI/DigitalGlobe).

Figure 2: Landsat observations of the study area. a) RGB color composite of Landsat 8 reflectance bands 5,6,7. Distinct zones are highlighted within the salars, which correlate with mineralogical variations (see text for more details). Green and red circles indicate the location of sampling sites, yellow lines delimit the location of the main salars (see figure 1). b) Landsat reflectance spectra collected on the Salar de Atacama halite-rich core (red), sulfate-rich margin (dark blue), clay-rich margin (cyan), on the water in the Salar de Tara (black) and on the sulfate-rich margin of the Salar de Laco (orange). A field spectrum (gypsum) collected at the Salar de Laco (brown) is shown for comparison. Field observations suggest that the lower average reflectance level at the Salar de Laco is due to the mixture of sulfates with a high proportion of detrital silicate material. c) The ratio between band 5 and band 7 can be utilized to highlight sulfate-rich areas, such as the Andean salars located along the Paso Sico road (south east). Colored squares indicate the location of the spectra shown in figure $2 \mathrm{~b}$. d) The ratio between band 4 and band 2 can be utilized to infer the effect of salt dilution on soils. High values (red tones) are attributed to iron-rich terrains (volcanic highlands), whereas the sedimentary bedrock of the Atacama basin as well as the Andean salars are characterized by lower values (blue tones).

Figure 3: Remote sensing views of the salars in the study areas and types of terrains. aClassification of crust types at the location visited in the field. b-i: Close-up of various salars. The squares indicate the location visited on the field. Colored numbers indicate different crust types as inferred from field and remote sensing data (DigitalGlobe images).

Figure 4: Field impressions and crust types. a to f: hard crust, type 1 (a to $d=$ Salar de Atacama, $a=$ J7L10, b=J7L9 with $\mathrm{c}$ and $\mathrm{d}$ being a wetter, transition zone (J7L11)) and type 2 (e,f = Laguna Tuyajto (J2L2R3)). g to i: soft, dry crust (type 3), g= Salar de Quisquiro (J11L1R4), h, i= Salar de Laco (J2L1R1). j,k,l: type 4 soft, moist crust (j= Laguna de Cejar (J9L1), k= Laguna Tuyajto $(\mathrm{J} 2 \mathrm{~L} 2 \mathrm{R} 2), \mathrm{l}=$ Salar de Quisquiro $(\mathrm{J} 11 \mathrm{~L} 1 \mathrm{R} 3)) . \mathbf{m , n , 0}$ : type 5 clay playa $\mathrm{m}, \mathrm{n}=$ northern Salar de 
Atacama (J8L1), o= Laguna Tuyajto (J2L2R4) .p, q: type 6 beach pebbles at Salar de Aguas Calientes 3 (J5L1R3).

Figure 5: VNIR reflectance spectra of selected field samples are compared with reference library spectra (Source: USGS spectral library, unless specify otherwise). a- Gypsum-bearing spectra from the Salar de Aguas Calientes 3 (J5L1R3, J5L1R4), laguna Tuyajto (J2L2R2) and laguna de la Piedra (J9L2R3). The rounded $1.9 \mu \mathrm{m}$ band in samples J5L1R3 and J9L2R3 is best matched by a mixture of gypsum and another hydrated material such as the hydrated halite presented in b. b- Featureless, water-bearing spectra of samples from the Salar de Atacama (J1L1R1), Salar de Quisquiro (J11L1R4), Laguna Tuyajto (J2L2R3), laguna de la Piedra (J9L2R1) are all consistent with hydrated material, which is identified by morphologic observations as (hydrated) halite. c- Shifted water absorptions in some samples from the Salar de Atacama (J7L10, J7L14) and a kink at $2.24 \mu \mathrm{m}$ are more consistent with $\mathrm{MgCl}_{2}$ (reference spectra from Bishop et al., 2014c). d- In the central part of the Salar de Atacama, and in the marginal area of laguna Chaxa, mixtures of pinnoite and ulexite (J1L1R4) and halite and pinnoite (J1L1R3) can be inferred from VNIR spectra. e- Absorptions in the spectra collected at laguna Tuyajto (J2L2R4) and various locations of the Salar de Atacama (J7L4, J7L8, J8L1, J1L1R5) are consistent with mixed halite and Al-rich clays such as montmorillonite (e.g., J7L4). The width of the $1.4 \mu \mathrm{m}$ absorption feature suggest the additional presence of $\mathrm{Ca}$ or $\mathrm{Na}$ sulfates such as gypsum or mirabilite in samples J7L8 and J2L2R4. f- Absorptions in spectrum J1L1R2 are consistent with a mixture of hydrated halite (such as in J1L1R1) and carbonates such as aragonite (reference spectra from Bishop et al., 2013).

Figure 6: a- Raman spectra of a subset of samples that showed interesting peaks. b- Reference library spectra of the minerals commonly identified in the samples are given for comparison. The black dashed line indicate the location of the main gypsum peak at 1007, which is detected in most samples.

Figure 7: XRD patterns of a set of representative samples. The strongest peaks are identified for each sample. $\mathrm{Hal}=$ halite, Gyp $=$ gypsum, $\mathrm{Qz}=$ quartz, $\mathrm{Anh}=$ anhydrite, The $=$ thenardite, $\mathrm{Ul}=$ 
ulexite, Pin = pinnoite, Do = dolomite, Alb = albite, Cal = calcite, Hydg= hydroglauberite, Gla = glauberite, Mir $=$ mirabilite, $\mathrm{An}=$ anorthite, Bass= bassanite.

Figure 8: Comparison of the mineralogy (“dominant" mineral phase in each sample) inferred from various instrument data (also see table 3). a) Spectrally dominant mineral as interpreted from the VNIR spectra, b) Spectrally dominant mineral as interpreted from Raman spectra (superimposed black points indicate the presence of carotenoids), c) Dominant mineral (= most abundant in this case) as interpreted from XRD patterns. Outlines of the salars are colored according to the type of brines they originate from (blue $=\mathrm{Ca}-$ rich, red $=\mathrm{SO} 4$-rich, magenta $=$ mixed brines (from Risacher et al., 2003)). There is a general agreement between the various instrument data, although some minerals can be masked or dominate the VNIR spectra when mixed with other material (see section $5.1)$.

Figure 9: Example of salt-rich deposits on Mars (Context Camera images at 6 meters/pixel, Mars Reconnaissance Orbiter mission). a) Sulfate-rich salt pans and karstic features in the Meridiani Planum region of Mars (modified after Flahaut et al., 2015), b) Sulfate-rich deposits of groundwater origin deposited on a bench in the Columbus crater wall (modified after Wray et al., 2011), c) Proposed chloride-bearing deposits from Osterloo et al. (2010), located in a topographic low south of the Meridiani Planum area (Colorized MOLA elevation is projected in transparency over CTX imagery, elevations range from $-1800 \mathrm{~m}$ (blue) to $-1000 \mathrm{~m}$ (red)). Proposed chloride-bearing deposits from Osterloo et al. (2010), located in the Terra Sirenum region of Mars (Colorized MOLA elevation is projected in transparency over CTX imagery, elevations range from $2100 \mathrm{~m}$ (blue) to $3200 \mathrm{~m}($ red)). 

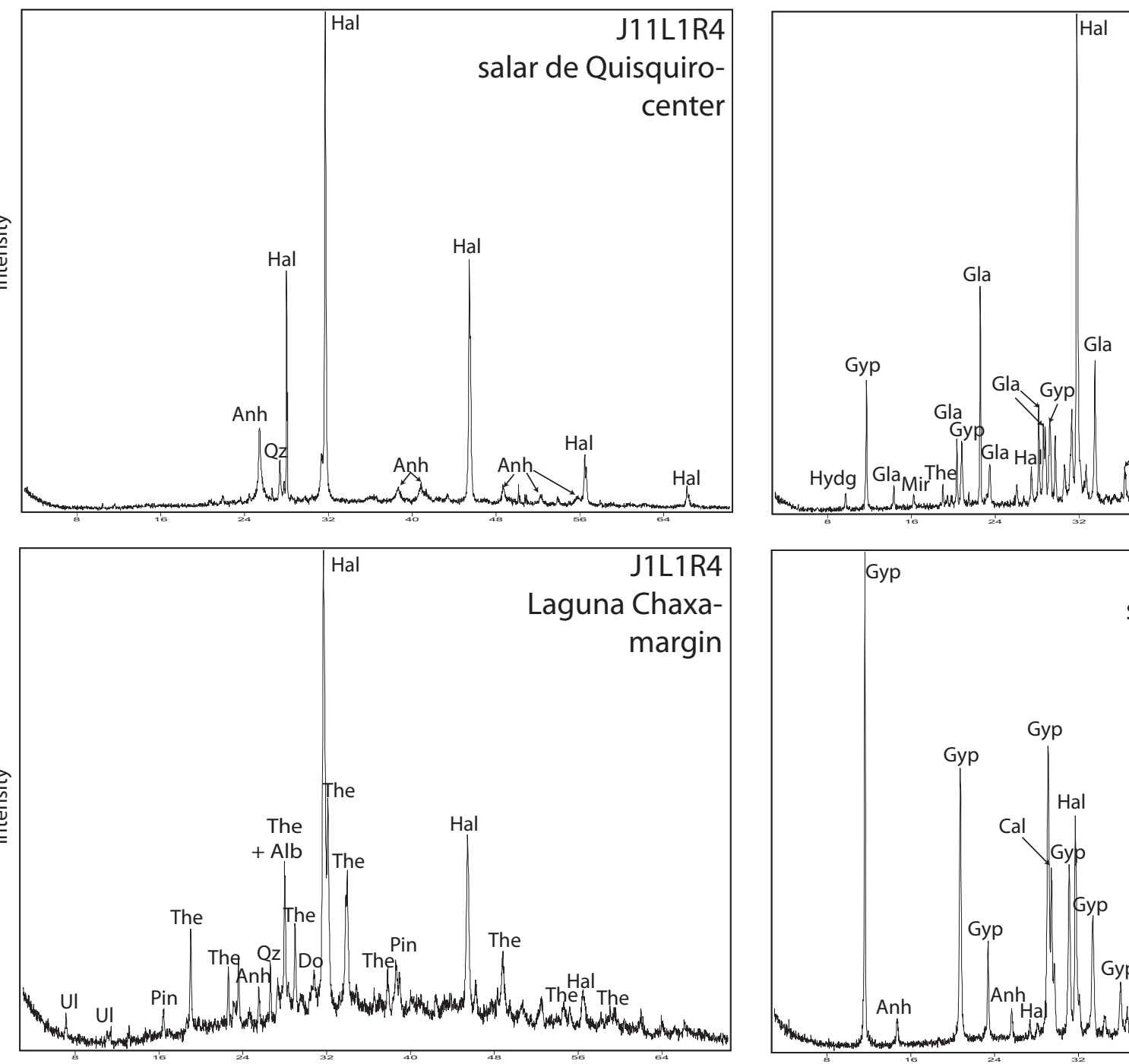

salar de Atacama-

E margin

Alb

Cal

Qz Alb

1 $\quad$ Hal Qz Alb Qz Qz
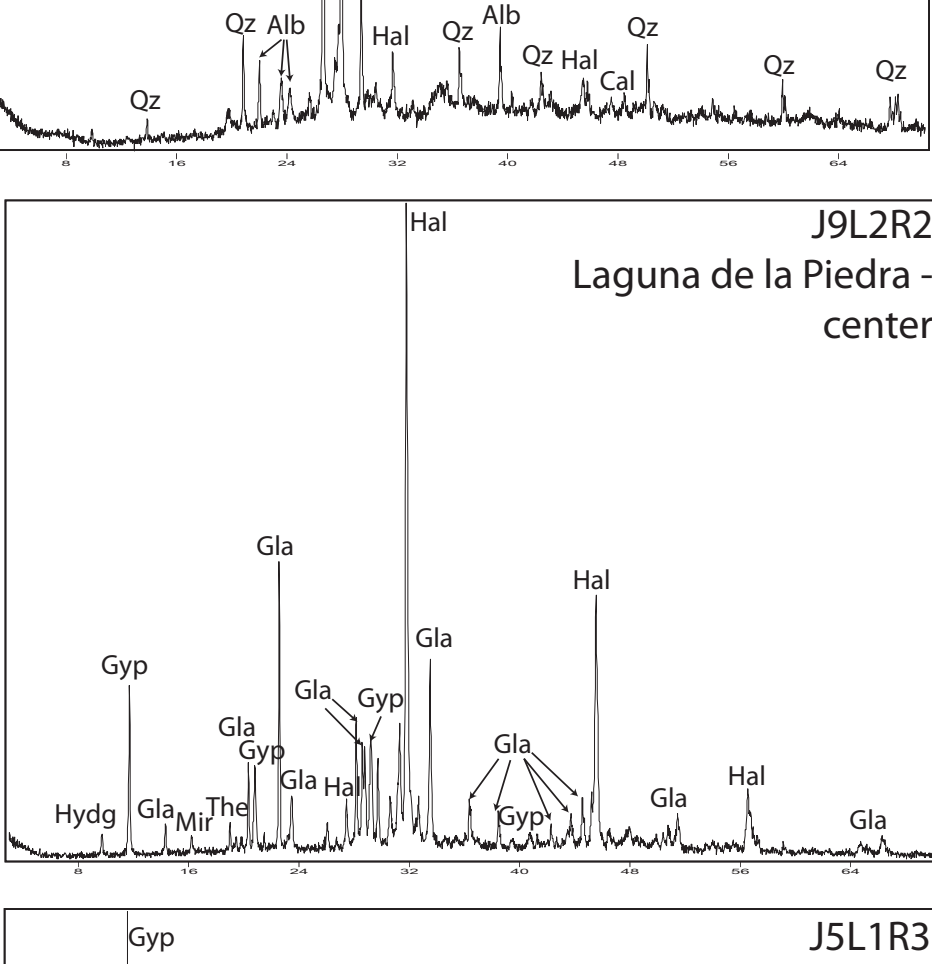

salar de Aguas Calientes 3-

center center 
a

Samples Raman spectra

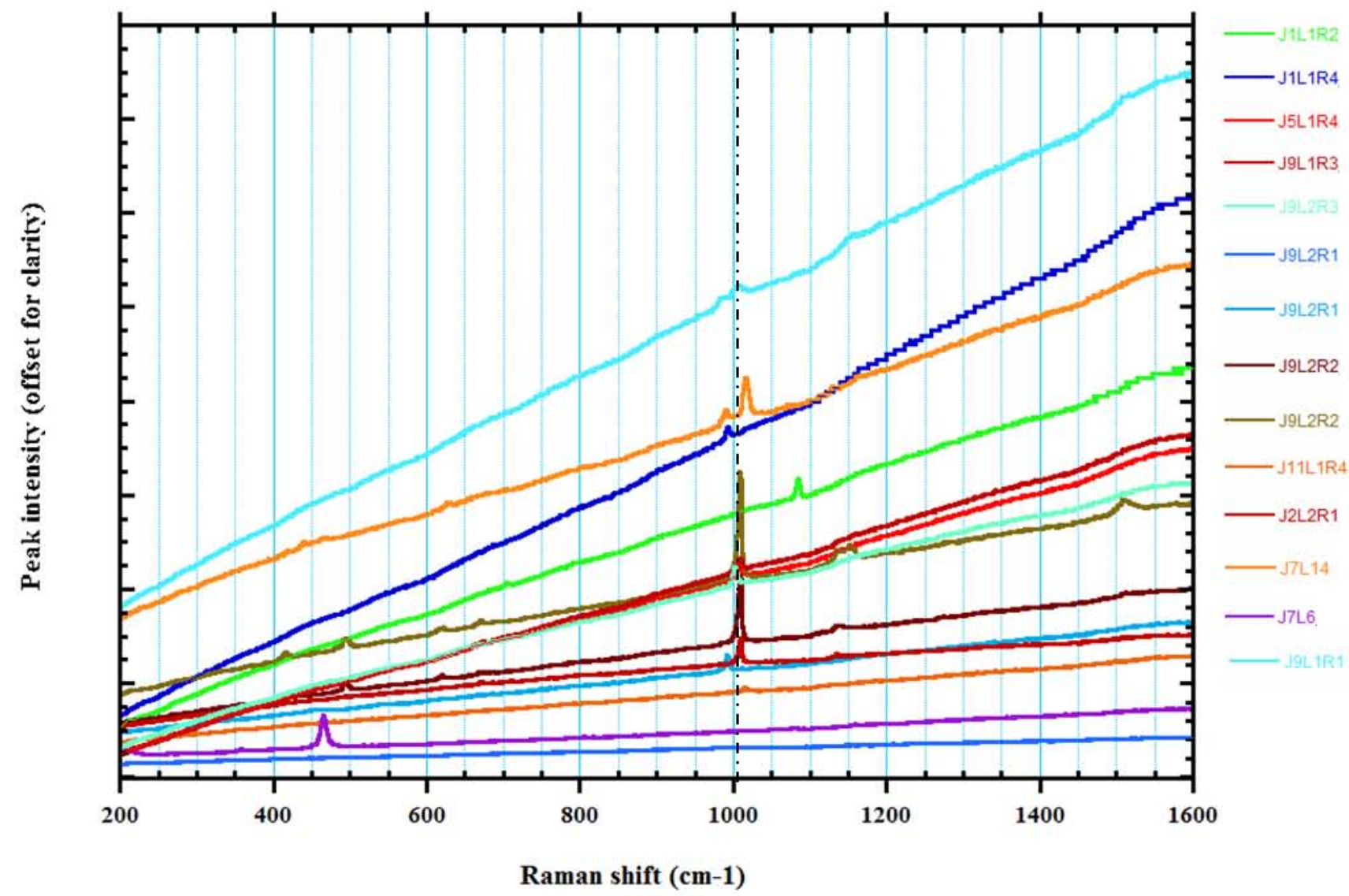

b

Library Raman spectra

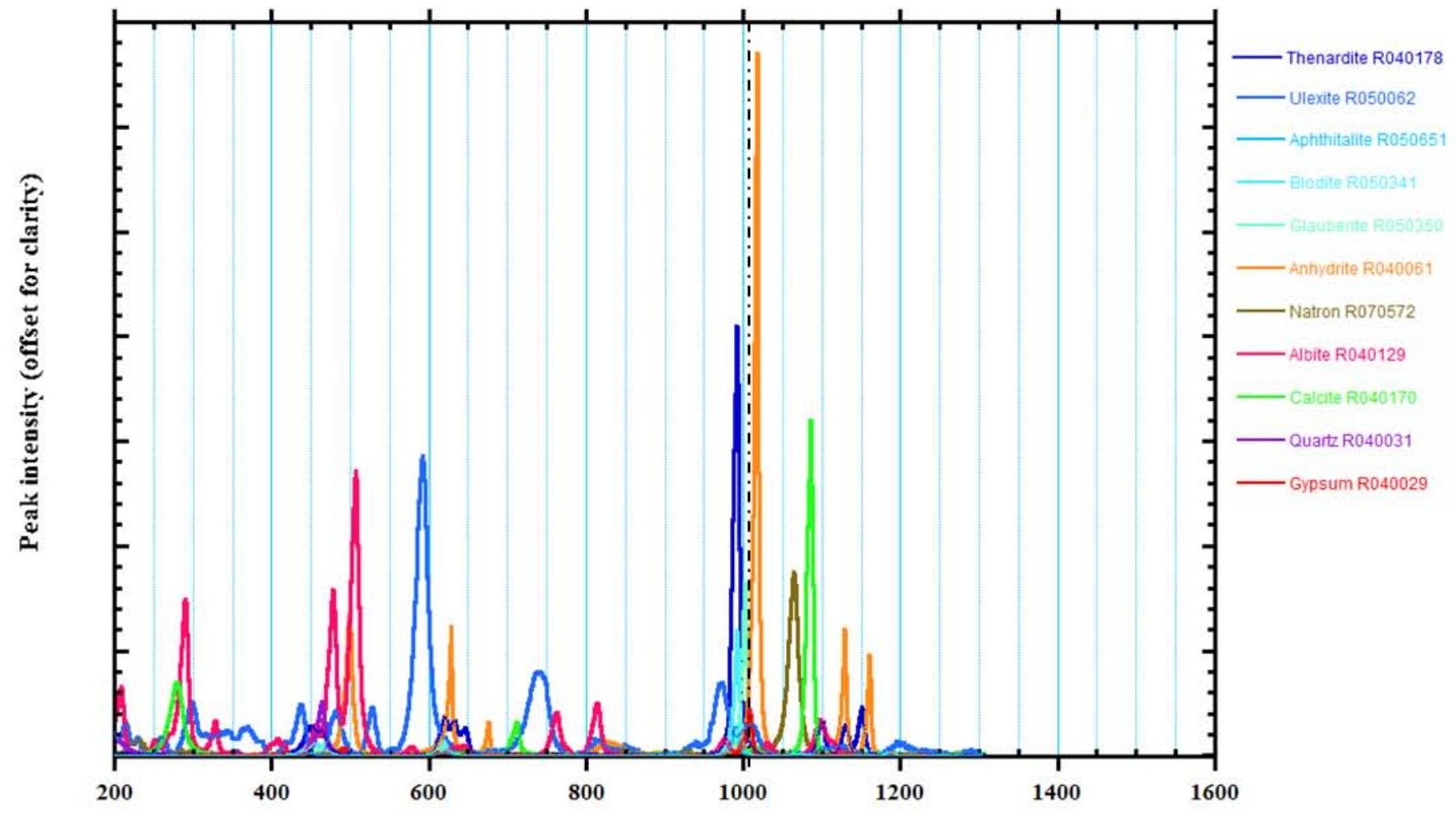

Raman shift (cm-1) 


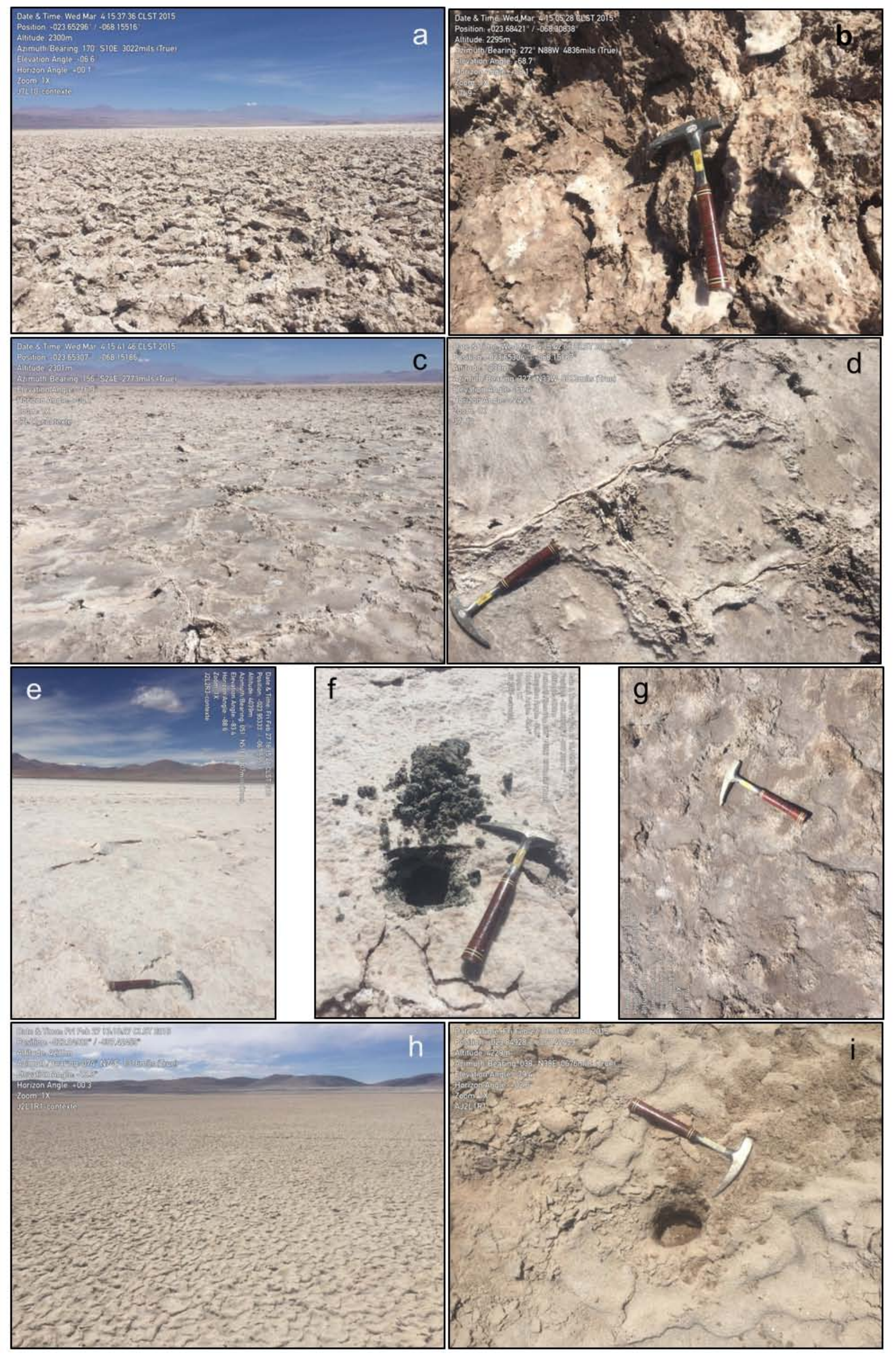




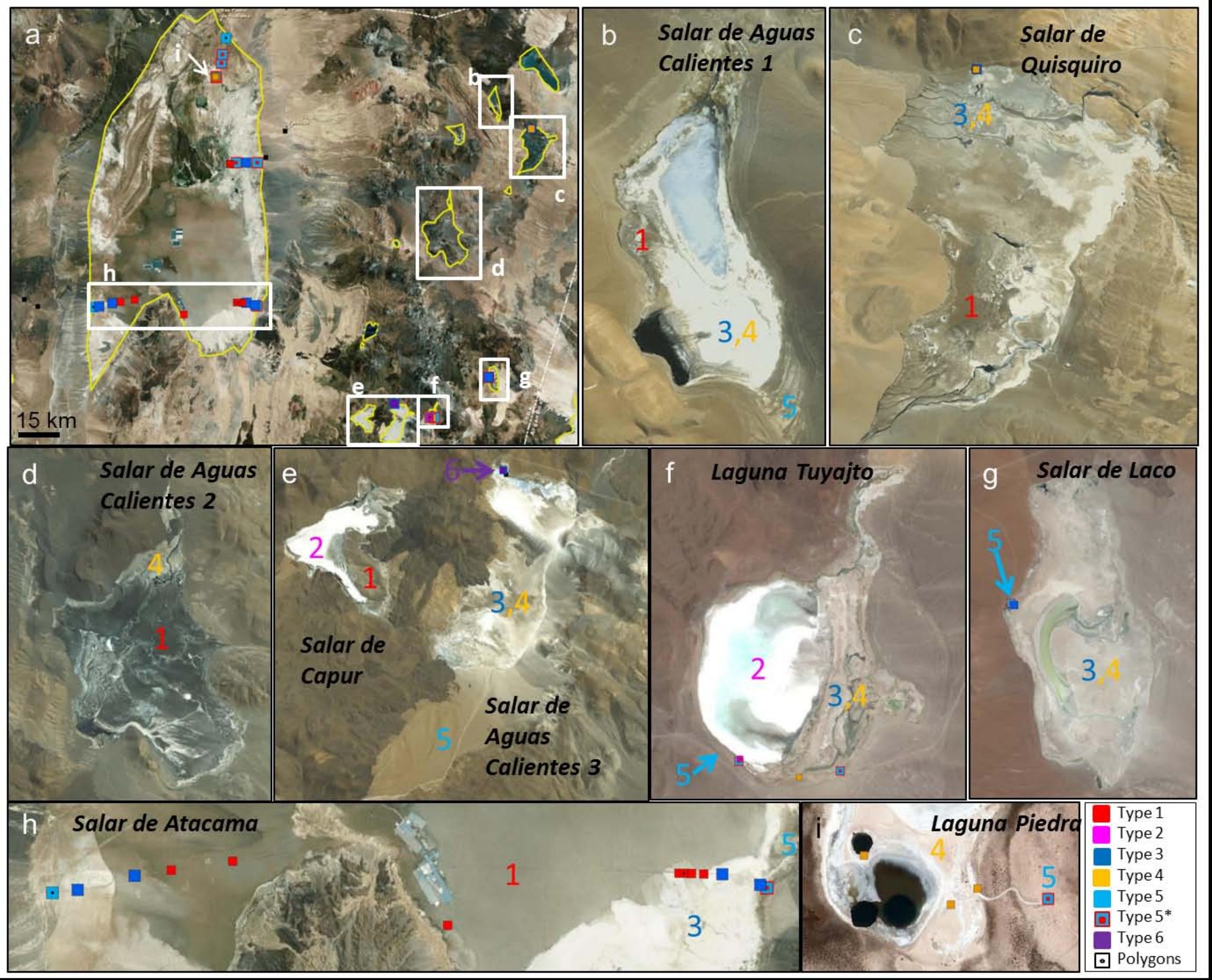




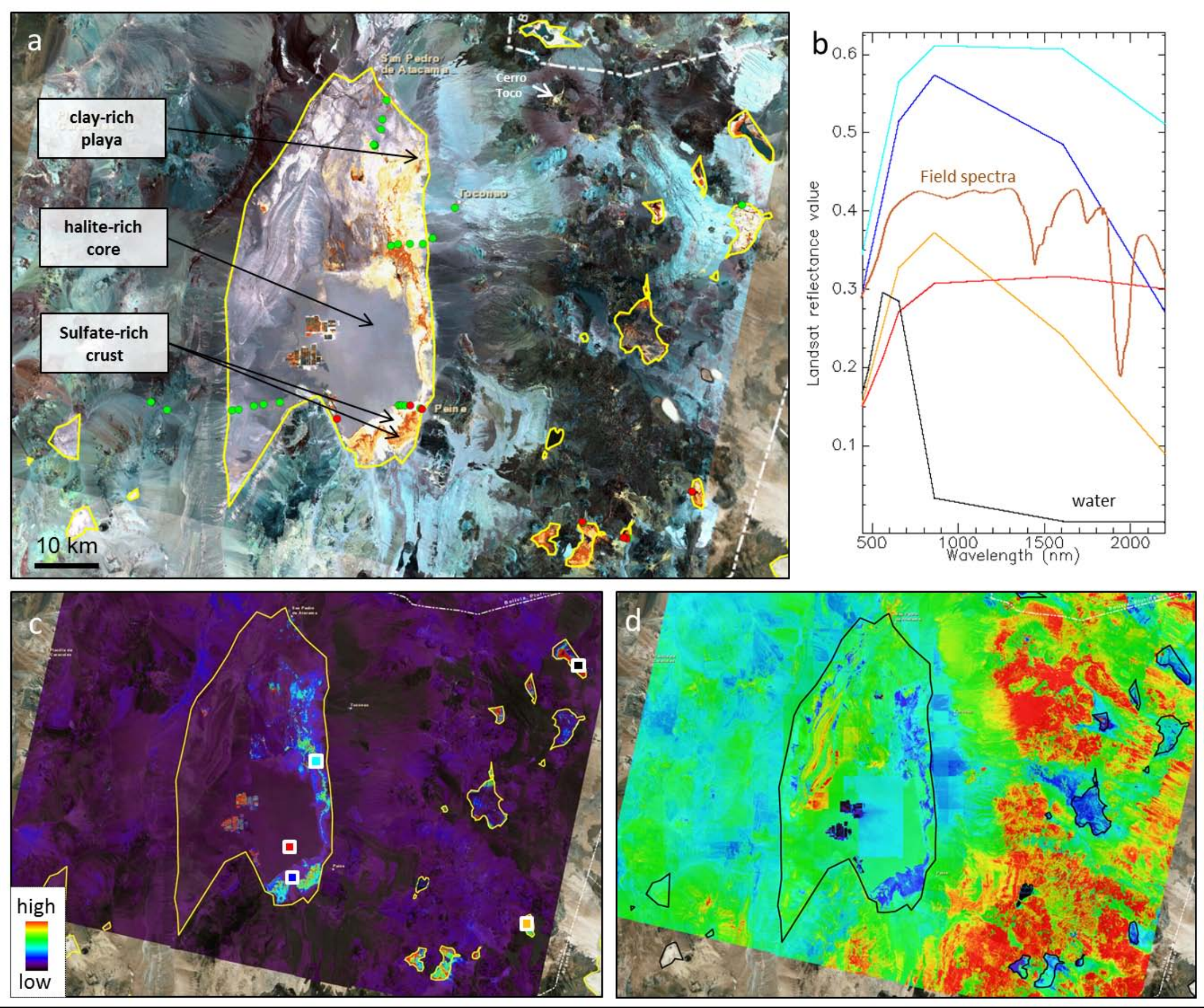



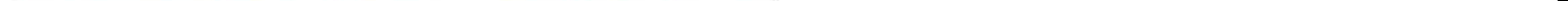

Inferred mineralogy:

Na sulfates

PHS/halite

Anorthite/Albite

C Carbonates

Clays

Gypsum

Mixed $\mathrm{Na} / \mathrm{Ca}$ sulfates

Borates
Brine type:

$\square \mathrm{Ca}$

\section{$\square \mathrm{SO} 4$}

$\square$ mixed 


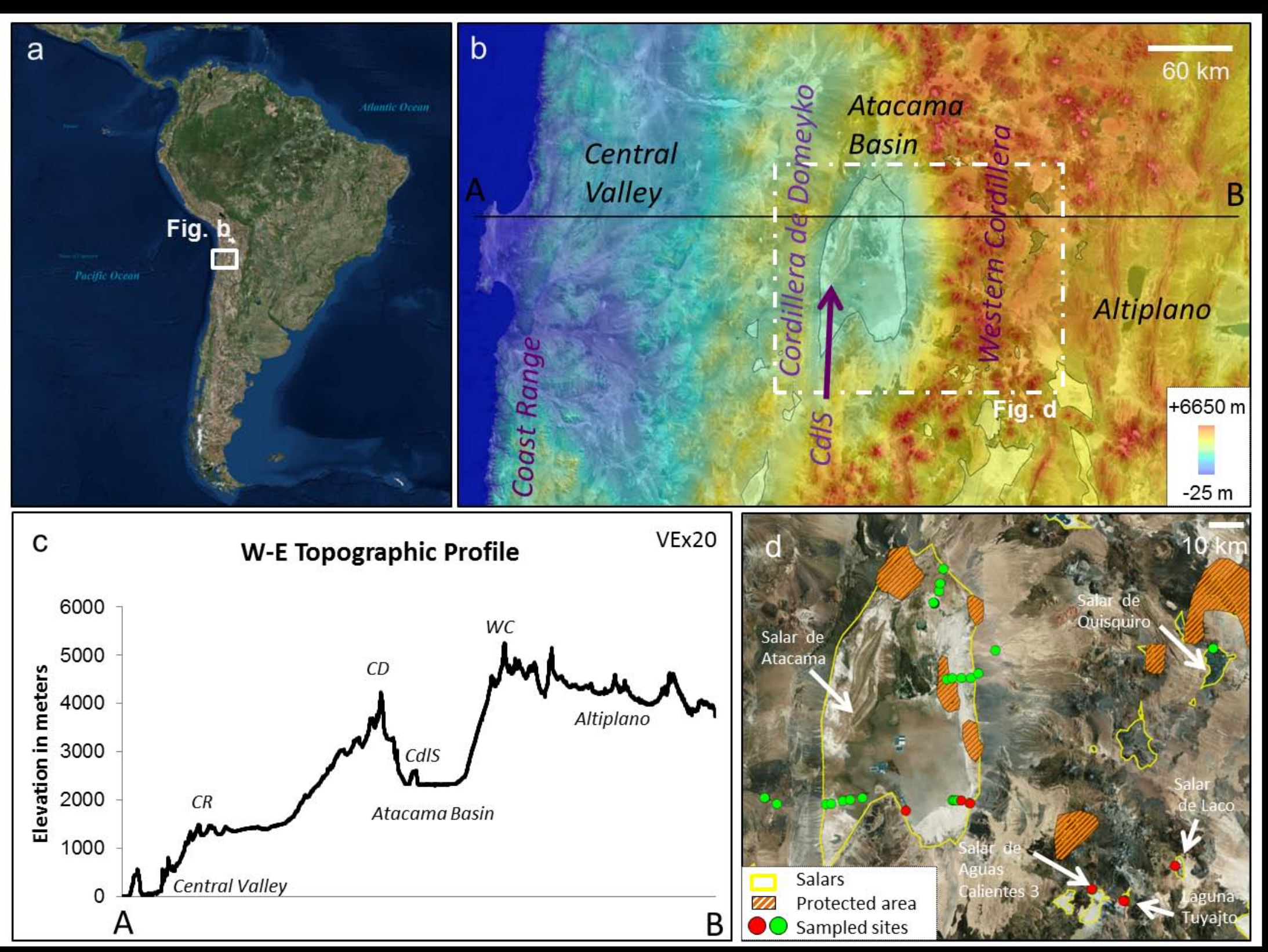




\begin{tabular}{|c|c|c|c|c|c|c|c|}
\hline salar name & brine type & $\begin{array}{c}\text { mean elevation } \\
(\mathrm{m})\end{array}$ & $\begin{array}{c}\text { mean temperature } \\
\left({ }^{\circ} \mathrm{C}\right)\end{array}$ & $\begin{array}{c}\text { evaporation } \\
(\mathbf{m m} / \mathbf{y r})\end{array}$ & $\begin{array}{l}\text { area salar } \\
(\mathbf{k m} 2)\end{array}$ & corresponding samples & $\begin{array}{l}\text { corresponding } \\
\text { figures }\end{array}$ \\
\hline $\begin{array}{l}\text { Salar de Aguas } \\
\text { Calientes } 3\end{array}$ & mixed & 3950 & 1 & 1500 & 46 & J5L1R3 (center), J5L1R4 (margin) & $3 e, 4 p, q$ \\
\hline Laguna Tuyajto & $\mathrm{SO}_{4}$ & 4010 & 1 & 1500 & 2.9 & $\begin{array}{l}\text { J2L1R1 (far margin), J2L2R2 (water pond, margin), J2L2R3 } \\
\text { (center), J2L2R4 (margin) }\end{array}$ & $3 f, 4 e, f, k, o$ \\
\hline Salar de Laco & $\mathrm{SO}_{4}$ & 4250 & 1 & 1500 & 16.2 & J2L1R1 (center), J2L1R2 (margin) & 3g, 4h,i \\
\hline salar de Quisquiro & Ca & 4150 & 1 & 1500 & 80 & $\begin{array}{l}\text { J11L1R1, J11L1R2 (margins), J11L1R3 (water pond, margin), } \\
\text { J11L1R4 (center) }\end{array}$ & 3c, 4g,l \\
\hline Salar de Atacama & mixed & 2300 & 14 & 1800 & 3000 & $\begin{array}{l}\text { J8L1 (N margin), J7L4, J7L5, J7L6 (E margin), J7L7, J7L8, } \\
\text { J7L9, J7L10, J7L12 (center), J7L14, J7L16 (W margin) }\end{array}$ & 3h, 4a,b,c,d,m,n \\
\hline $\begin{array}{l}\text { Salar de Atacama - } \\
\text { Laguna Cejar }\end{array}$ & $\mathrm{SO}_{4}$ & & & & & J9L1R1, JEL1R2, J9L1R3 (center), J9L1R4, J9L1R5 (margin) & $4 j$ \\
\hline $\begin{array}{l}\text { Salar de Atacama - } \\
\text { Laguna Piedra }\end{array}$ & $\mathrm{SO}_{4}$ & & & & & $\begin{array}{l}\text { J9L2R1 (pond), J9L2R2, J9L2R3 (center), J9L1R4, J9L1R5 } \\
\text { (margin) }\end{array}$ & $3 \mathrm{i}$ \\
\hline $\begin{array}{l}\text { Salar de Atacama - } \\
\text { Laguna Chaxa }\end{array}$ & $\mathrm{SO}_{4}$ & & & & & J1L1R1, J1L1R2 (center), J1L1R3, J1L1R4, J1L1R5 (margin) & \\
\hline
\end{tabular}




\begin{tabular}{|c|c|c|c|c|c|c|c|c|c|c|c|c|c|c|c|c|c|c|c|c|c|c|c|c|c|c|c|}
\hline sample origin location & crust type & sample name & cristallinity & Gyp & Hal & Cal & Ara & Do & Natri & Natro & An & Alb & Qz & Bass & Anh & Gla & Blo & The & Mir & Pin & $\mathrm{UI}$ & Nob & Sylv & Hydg & Hydp & $\mathbf{A l}$ & phyl \\
\hline Salar de Aguas Calientes 3 - center & T6 & A-J5L1R3Z1 & +++ & ++ & + & + & & & & & & & & & - & & & & & & & & & & & & \\
\hline Salar de Aguas Calientes 3 - center $-20 \mathrm{~cm}$ depth & & A-J5L1R3Z2 & +++ & +++ & - & - & & & - & & & & & & & & & & & & & & & & & & \\
\hline Salar de Aguas Calientes 3 - margin & T3 & A-J5L1R4Z1 & +++ & + & ++ & & & & & & + & & & & & & & & & & & & & & & & \\
\hline Salar de Aguas Calientes 3 - margin - $20 \mathrm{~cm}$ depth & & A-J5L1R4Z2 & +++ & +++ & - & - & & & & & & & & & & & & & & & & & & & & & \\
\hline Laguna Tuyajto - center & $\mathrm{T} 2$ & A-J2L2R3Z1 & +++ & + & +++ & & & & & & & & & & & & & & & & & & & & & & \\
\hline Laguna Tuyajto - center $-20 \mathrm{~cm}$ depth & & A-J2L2R3Z2 & ++ & ++ & + & + & - & & & & + & & - & & & & & & & & & & & & & & \\
\hline Laguna Tuyajto - margin & $T 5^{*}$ & A-J2L2R4Z1 & +++ & - & +++ & - & & & & & + & & 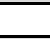 & & & & & & & & & & & & & & \\
\hline Laguna Tuyajto - margin - $20 \mathrm{~cm}$ depth & & A-J2L2R4Z2 & + & & - & - & & & & & +++ & & - & & & & & & & & & & & & & & \\
\hline Laguna Tuyajto - margin & $\mathrm{T} 4$ & A-J2L2R2 & ++ & ++ & ++ & + & & & & & + & & & & & & & & & & & & & & & & \\
\hline Laguna Tuyajto - margin & $T 5^{*}$ & A-J2L2R1 & ++ & ++ & ++ & - & & & & & - & & - & & & & & & & & & & & & & & \\
\hline Salar de Laco - center & $\mathrm{T} 3$ & A-J2L1R1Z1 & ++ & ++ & + & & & & & & + & & - & - & & & & & & & & & & & & & \\
\hline Salar de Laco - center $-20 \mathrm{~cm}$ depth & & A-J2L1R1Z2 & ++ & ++++ & - & & & & & & + & & - & & & & & & & & & & & & & & \\
\hline Salar de Laco - margin & T5* & A-J2L1R2Z1 & ++ & + & + & + & & & & & + & & - & & & & & & & & & & & & & & \\
\hline Salar de Laco - margin - $20 \mathrm{~cm}$ depth & & A-J2L1R2Z2 & + & & - & + & & & & & ++ & & + & & & & & & & & & & & & & & \\
\hline Salar de Laco - margin - $20 \mathrm{~cm}$ depth former crust & & A-J2L1R2Z2crust & ++ & - & & + & ++ & & & & & - & - & & & & & & & & & & & & & & \\
\hline Salar de Atacama - N margin & $T 5$ & J8L1 & + & & - & & & & & & & ++ & + & & & & & & & & & & & & & & + \\
\hline Salar de Atacama - Laguna de Cejar -center & T4 & J9L1R1 & +++ & ++ & + & + & & & & & & & & & & + & & & & & & & & & & & \\
\hline Salar de Atacama - Laguna de Cejar -center & T4 & J9L1R2 & +++ & & +++ & & & & & & & & & & & & & & & & & & & & & & \\
\hline Salar de Atacama - Laguna de Cejar -center & $\mathrm{T} 4$ & J9L1R3 & +++ & ++ & + & + & & & & & & & - & & & - & & & & & & & & & & & \\
\hline Salar de Atacama - Laguna de Cejar/de la Piedra -margin & $T 5^{*}$ & J9L1R4 & ++ & - & + & + & & & & - & + & & - & & - & -1 & & & & & & & & & & & \\
\hline Salar de Atacama - Laguna de Cejar/de la Piedra -margin & $T 5^{*}$ & J9L1R5 & +++ & + & ++ & - & & & & & & - & - & + & & - & & & & & & & & & & & \\
\hline Salar de Atacama - Laguna de la Piedra -center - ponds & T4 & J9L2R1 & +++ & + & + & & & & & & & & & & & ++ & - & - & - & & & & . & - & - & & \\
\hline Salar de Atacama - Laguna de la Piedra -center & $T 4$ & J9L2R2 & +++ & + & + & & & & & & & & 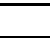 & & & ++ & - & - & - & & & & & - & - & & \\
\hline Salar de Atacama - Laguna de la Piedra -center & T4 & J9L2R3 & +++ & ++++ & - & & & & & & & & 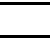 & & & & & & & & & & & & & & \\
\hline Salar de Atacama - Laguna Chaxa -center & $\mathrm{T} 1$ & J1L1R1 & +++ & - & +++ & & & & & & & - & - & & - & & & & & & & & - & & & & \\
\hline Salar de Atacama - Laguna Chaxa -center & $T 1^{*}$ & J1L1R2 & ++ & & - & & +++ & & & & & & & & & & & & & & & & & & & & \\
\hline Salar de Atacama - Laguna Chaxa -margin & T5* & J1L1R3 & ++ & & + & & & & & & & + & - & & & & & & & & ++ & & - & & & & \\
\hline Salar de Atacama - Laguna Chaxa -margin & $T 3$ & J1L1R4 & ++ & & + & & & - & & & & + & - & 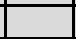 & - & & & + & & + & + & - & & & & & \\
\hline Salar de Atacama - Laguna Chaxa -margin & $T 5^{*}$ & J1L1R5 & ++ & & + & & & & & & + & & + & - & - & + & & & & & & & & & & & \\
\hline salar de Quisquiro - margin & $\mathrm{T} 4$ & J11L1R1 & ++ & + & ++ & & & & & & - & & - & + & & & & & & & & & & & & & \\
\hline salar de Quisquiro - margin & $T 4$ & J11L1R2 & ++ & + & ++ & & & & & & - & & - & + & & & & & & & & & & & & & \\
\hline salar de Quisquiro - margin (water pond) & T4 & J11L1R3 & ++ & + & ++ & & & & & & - & & - & + & & & & & & & & & & & & & \\
\hline salar de Quisquiro - center & $\mathrm{T3}$ & J11L1R4 & ++ & & ++ & & & & & & + & & - & & + & & & & & & & & & & & & \\
\hline Salar de Atacama - E margin & $T 5$ & J7L4 & ++ & & - & + & - & & & & & + & + & & & & & & & & & & & & & & - \\
\hline Salar de Atacama - E margin & T3 & J7L5 & +++ & & +++ & - & & & & & & - & - & & - & & & & & & & & & & & & \\
\hline Salar de Atacama - E margin & $T 3$ & J7L6 & +++ & & ++ & & & & & & & + & + & & - & & & & & & & & & & & & - \\
\hline Salar de Atacama -center & $\mathrm{T} 1$ & J7L7 & +++ & & +++ & & & & & & & - & - & & - & & & & & & & & & & & & \\
\hline Salar de Atacama -center & $T 1$ & J7L8 & +++ & & ++++ & & & & & & & & - & & - & & & & & & & & - & & & & \\
\hline Salar de Atacama -center & $\mathrm{T} 1$ & AJ7L9 & +++ & & +++ & & & & & & & & - & & - & & & & & & & & & & & & \\
\hline Salar de Atacama -center & T1 & J7L10 & +++ & & +++ & & & & & & & & & & & & & & & & & & & & & & \\
\hline Salar de Atacama -center & $\mathrm{T} 1^{*}$ & J7L11 & +++ & & +++ & & & & & & & & & & & & & & & & & & & & & & \\
\hline Salar de Atacama -center & $\mathrm{T} 1$ & J7L12 & +++ & & +++ & & & & & & & & & & & & & & & & & & - & & & & \\
\hline Salar de Atacama -W margin & $T 3$ & A-J7L14 & +++ & & +++ & & & & & & & - & & & - & & & & & & & & & & & & \\
\hline Salar de Atacama -W margin & $T 5^{*}$ & A-J7L16Z1 & ++ & & - & & & & & & & + & + & & ++ & & & & & & & & & & & & \\
\hline Salar de Atacama -W margin $-20 \mathrm{~cm}$ depth & & A-J7L16Z2 & ++ & + & + & & & & & & & + & + & & - & & & & & & & & & & & & \\
\hline & & & & & & & & & & & & & & & & & & & & & & & & & & & \\
\hline
\end{tabular}




\begin{tabular}{|c|c|c|c|c|}
\hline Sample ID & Context & VNIR dominant mineral & Raman dominant mineral & most abundant mineral from XRD \\
\hline J1L1R1 & Salar de Atacama - core area & PHS & anhydrite & halite \\
\hline J1L1R2 & Salar de Atacama - core area, small concretions & carbonate + PHS & carbonate & carbonate \\
\hline J1L1R3 & Salar de Atacama - margin, east of Laguna Chaxa & pinnoite + PHS & $\mathrm{N}$ & borate \\
\hline J1L1R4 & Salar de Atacama - margin, east of Laguna Chaxa & ulexite + pinnoite & Na-sulfate & Na-sulfate \\
\hline J1L1R5 & Salar de Atacama - margin, east of Laguna Chaxa & PHS + clays & $\mathrm{N}$ & anorthite \\
\hline J2L1R1 & Salar de Laco - core area & gypsum & gypsum & gypsum \\
\hline J2L1R2 & Salar de Laco - margin area & gypsum + PHS & gypsum + C & anorthite \\
\hline J2L2R1 & Laguna Tuyajto - far margin area & gypsum & gypsum & gypsum \\
\hline$J 2 L 2 R 2$ & Laguna Tuyajto - far margin area (wet) & gypsum & gypsum & halite \\
\hline J2L2R3 & Laguna Tuyajto - core area & PHS & gypsum + C & halite \\
\hline J2L2R4 & Laguna Tuyajto - margin area & PHS + clays + sulfates & $\mathrm{N}$ & halite \\
\hline J5L1R3 & salar de Aguas Calientes 3 - 'beach' area & gypsum + PHS & gypsum & gypsum \\
\hline J5L1R4 & salar de Aguas Calientes 3 - margin area & gypsum & gypsum & halite \\
\hline J7L4 & salar de Atacama - margin area & PHS + clays & carbonate & albite + clays \\
\hline J7L5 & salar de Atacama - margin area & clays + PHS & anhydrite & halite \\
\hline J7L6 & salar de Atacama - core area & PHS + clays & unindentified peak at 150 & halite \\
\hline J7L7 & salar de Atacama - core area & PHS + clays + sulfates & $\mathrm{N}$ & halite \\
\hline J7L8 & salar de Atacama - core area & PHS + clays + sulfates & anhydrite & halite \\
\hline J7L9 & salar de Atacama - core area & PHS + sulfates & $\mathrm{N}$ & halite \\
\hline J7L10 & salar de Atacama - core area & PHS (MgCl2?) & anhydrite & halite \\
\hline J7L11 & salar de Atacama - core area & PHS + sulfates & anhydrite & halite \\
\hline J7L12 & salar de Atacama - core area & PHS + clays & $\mathrm{N}$ & halite \\
\hline J7L14 & salar de Atacama - margin area & PHS (MgCl2?) & anhydrite & halite \\
\hline J7L16 & salar de Atacama - margin area & Na-sulfate & $\mathrm{N}$ & albite \\
\hline J8L1 & salar de Atacama - margin area & PHS + clays + gypsum & 150 peak & albite + clays \\
\hline J9L1R1 & laguna de Cejar - core area & PHS & gypsum + Na-sulfate $+C$ & gypsum \\
\hline J9L1R2 & laguna de Cejar - core area & PHS & Na-sulfate $+\mathrm{C}$ & halite \\
\hline J9L1R3 & laguna de Cejar - core area & gypsum & gypsum + Na-sulfate & gypsum \\
\hline J9L1R4 & laguna de Cejar - marginal area & gypsum + clays & $\mathrm{N}$ & halite \\
\hline J9L1R5 & laguna de Cejar - marginal area & gypsum + sulfates & gypsum & halite \\
\hline J9L2R1 & laguna de la Piedra - core area, pool of white crystals & PHS & Na-sulfate & halite \\
\hline J9L2R2 & laguna de la Piedra - core area & Na-sulfate & gypsum + C & Na-sulfate \\
\hline J9L2R3 & laguna de la Piedra - core area, ramparts & gypsum + PHS & gypsum + C & gypsum \\
\hline J11L1R1 & salar de Quisquiro - margin area & PHS & gypsum + C & halite \\
\hline J11L1R2 & salar de Quisquiro - margin area & gypsum + PHS & gypsum & halite \\
\hline J11L1R3 & salar de Quisquiro - margin area (wet) & gypsum + PHS & gypsum + C & gypsum \\
\hline J11L1R4 & salar de Quisquiro - core area & PHS & anhydrite & halite \\
\hline
\end{tabular}

